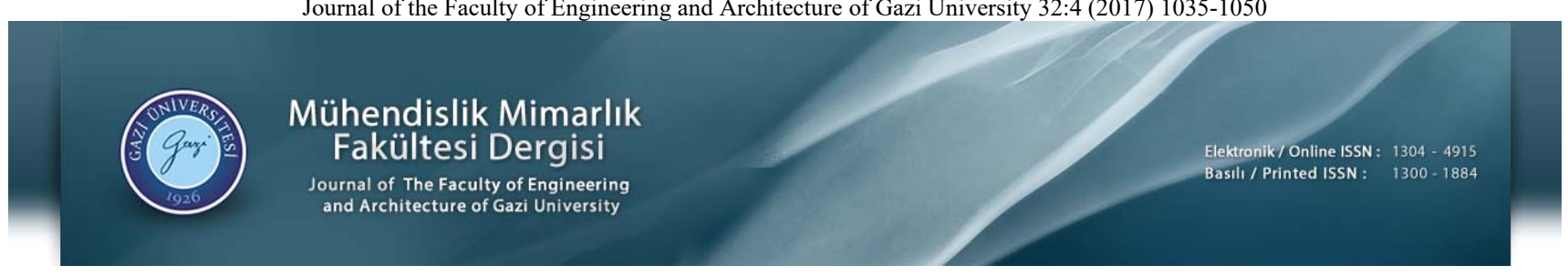

\title{
Çırpan kanadın aerodinamik parametrelerinin deneysel olarak incelenmesi
}

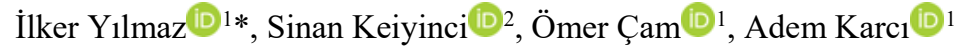 \\ ${ }^{1}$ Uçak Gövde Motor Bölümü, Havacılık ve Uzay Bilimleri Fakültesi, Erciyes Üniversitesi, Melikgazi, Kayseri, 38039, Türkiye \\ ${ }^{2}$ Sivil Havacılık Yüksekokulu, Çukurova Üniversitesi, Sarıçam, Adana, 01380, Türkiye
}

\section{Ö N E Ç I K A N L A R}

- Çırpan kanat mekanizmasının tasarımı

- Aerodinamik parametrelerinin deneysel incelenmesi

- $\quad$ Farklı çırpma frekanslarının itki ve sürtünme üzerine etkisi

Makale Bilgileri

Gelis: 21.04.2016

Kabul: 19.07.2017

DOI:

10.17341/gazimmfd.369354

Anahtar Kelimeler:

Çırpan kanat, mikro hava arac1, daimi olmayan akış, rüzgâr tüneli

\section{ÖZET}

İnsansız hava araçlarının kullanım alanlarının artması bu alanda yapılan çalıșmaların sayısını artırmıștır. İnsansız hava araçlarının daha küçük modelleri olan mikro hava araçları sivil ve askeri birçok alanda kullanılmaktadır. Mikro hava araçları temel olarak sabit, döner ve çırpan kanatlı olarak üçe ayrılır. Bu çalışmada incelenen çırpan kanatlı hava araçlarının en önemli avantajı, itki kuvvetinin kanatların çırpma hareketi sonucu oluşur ve böylece harici bir itki sistemine ihtiyaç duyulmaz. Bu çalışmanın amacı çırpan kanatlardaki daimi olmayan akışı rüzgâr tünelinde deneysel olarak incelemektir. Çalıșma kapsamında bir çırpan kanat mekanizması oluşturulmuş ve farklı malzemelerden üretilen kanatlar çırpma hareketi yaparken farklı hava hızı, hücum açısı ve çırpma frekanslarındaki aerodinamik parametreleri incelenmiştir. Elde edilen sonuçlara göre; yüksek hava hızı ve hücum açılarında taşıma kuvveti artarken, sürtünmenin artmasından dolayı itki kuvveti azalmaktadır. Yüksek çırpma frekanslarında itki kuvveti artarken taşıma kuvveti azalmıştır. Malzeme açısından değerlendirilirse, naylon ve lateks kanadın itki kuvvetlerinin ahşap kanattan daha iyi olduğu tespit edilmiştir.

\section{Experimental investigation of aerodynamic parameters on flapping wing}

\section{H I G H L I G H T S}

- Design of flapping wing mechanism

- Experimental investigation of aerodynamic parameters

- Effect of thrust and friction at different flapping frequencies

Article Info

Received: 21.04.2016

Accepted: 19.07.2017

DOI:

10.17341/gazimmfd.369354

Keywords:

Flapping wing, micro air vehicles, unsteady flow, wind tunnel

\section{ABSTRACT}

Increasing the application areas of unmanned aerial vehicles has increased the number of studies in this field. Micro air vehicles that are smaller models of the unmanned aerial vehicles are used in many areas of civil and military. Micro air vehicles are basically divided into three classes as fixed, rotary and flapping wings. The most important advantage of flapping wing air vehicles examined in this study, thrust force occurs as a result of flapping motion of the wings and thus an external thrust system is not required. The aim of this study, unsteady flow in flapping wings is to examine with experiments in wind tunnel. The scope of work a flapping wing mechanism was designed and the aerodynamics parameters at different wind speed, angle of attack and flapping frequencies were examined while the wings produced with different materials were flapping. According to the obtained results; while the lift force was increased at higher wind speed and angle attack, the thrust force was reduced because of friction. At high flapping frequency while the thrust force was increased, the lift force was decreased. If it is evaluated in terms of materials, thrust force of airfoils made of nylon sheet and latex airfoils are better than those of wood airfoils is found. 


\section{GIRISŞ (INTRODUCTION)}

Kuş uçuşunu taklit etmek yüzyıllar boyunca insanlığın vazgeçilmez bir arzusu olmuştur. Leonardo Da Vinci'nin çizimlerinden Otto Lilienthal'ın planörüne kadar, çırpan kanatlı uçuş araştırmalarının ilk beş yüz yılı insan taşımaya odaklanmıştır. Günümüzde teknolojinin de gelişmesi ile birlikte bu araştırmalar otonom ornitopter (kanat çırparak uçan) insansız hava aracı (İHA) ile çok daha küçük ölçekteki çalışmalara doğru yön değiştirmiştir.

Geleneksel İHA'ların kapalı alanlarda kullanılması gerektiği durumlarda bazı zorluklar ortaya çıkmıştır. Sabit kanatlı İHA'larda kanat alanı küçüldükçe aerodinamik verimliliğin azalması nedeniyle havada tutunabilmesi için hızın artırılması gerekmektedir. Bu sebeple sabit kanatlı İHA'ların kapalı alanlarda kullanımı uygun değildir. Döner kanatlı modellerde ise gürültülü çalışma durumu ve rotor pallerinin çok fazla küçültülememesi başlıca sorunlar olarak öne çıkmaktadır. Çırpan kanatlı modellerin düşük hızlardaki verimliliği, kıvraklığı ve sessiz çalışmaları sayesinde kapalı alanlarda ve yüksek manevra kabiliyeti istenen yerlerde kullanılmasının diğer iki modele göre daha uygun olduğu bilinmektedir [1]. Hava aracının boyutunun küçülmesi kanat yapısına bağlı olarak Reynolds sayısı da düşürmektedir. Kanat alanı azaldıkça, düşük Reynolds sayısına geçildiği için kanattan elde edilen performans önemli ölçüde azalmaktadır. $\mathrm{Bu}$ yüzden sabit kanatlı ve döner kanatlı İHA'ların aerodinamik verimliliği azalmaktadır. Sabit kanatlı İHA'larda kanat alanının negatif etkisini azaltıp gerekli taşımayı sağlamak için yüksek hızlarda çalışmasına ihtiyaç duyulmaktadır. Yüksek hızdan dolayı ise başarılı kapalı alan uçuşlarında gereken karmaşık manevraları yapmak çok daha fazla güçleşmektedir. Bunlara ek olarak sabit kanatlı İHA'lar kısa kalkış ve inişler, engellerden kaçınma ve buna benzer diğer durumlar için uygun değildir [2].

Tablo 1'de farklı tasarımlar ile üretilen İHA'ların dezavantaj ve avantajları bazı özellikler adı altında gösterilmiştir.

Çırpan kanatlı hava araçlarının düşük Reynolds sayılarında çalışmaları ve küçük gövdeli olmaları sebebiyle birçok araştırmacı bu konudaki çalışmalara yönelmiştir. Araştırmacılar çırpan kanatlı uçuşların karmaşık özelliklerini araştırmaya odaklanmışlardır. Bu araştırmalar; farklı hava aracı tasarımlarını, bu tasarımların analitik modellerinin türetilmesini, nümerik simülasyonları ve deneysel çalışmaları içermektedir. Pourtakdoust vd. [3], Hsu vd. [4],
Lin vd. [5], Mukherjee vd. [6] ile Tsai vd. [7] tarafindan yapılan araştırmalar çırpan kanatlı İHA tasarımlarını, üretim tekniklerini ve geliştirilmesini kapsamaktadır. Bu çalışmalarda farklı frekans, hız ve hücum açıları için çırpan kanatların kütle, kütlesel atalet kuvvetleri, elastik özellikleri, aerodinamik yükler (itki ve taşıma), çırpma genliği ve çırpma frekansının yanı sıra birçok geometrik ve tasarım parametrelerin arasındaki bağlantılar araştırılmıştır. Karakaş vd. [8] dört farklı profile sahip kanat modellerine niteliksel olarak itki veya sürükle kuvvetinin oluştuğu hareket durumlarında kanat açıklığı boyunca niceliksel akım görüntüleme ve eşzamanlı kuvvet ölçümleri yapmışlardır. $\mathrm{Bu}$ çalışmada değişik kanat profilleri kullanımının vorteks oluşumları ile itki/sürükleme elde edilmesinde oluşturduğu farklılıkları incelemişler ve genel olarak niceliksel akım görüntüleme sonuçlarına dayanarak kanat kesit şeklinin etkisinin görülemediğini ortaya koymuşlardır. Liu vd. [9] hafif bir mikro hava aracı tasarlayıp, üretmişler ve gökyüzünde başarılı bir şekilde uçurmuşlardır. Ayrıca bu çalışmada hesaplamalı akışkanlar dinamiği (HAD) metodunu kullanarak 2 boyutlu esnek çırpan kanat modeli geliştirilmiş daimî olmayan aerodinamik konusunda incelemeler yapılmıştır. Sonuç olarak hücum kenar vortekslerinin tipik bir çırpan kanatlı mikro hava aracına yetecek kadar taşıma üretebildiğini belirtmişlerdir. Aynı çalışmada esnek kanadın taşıma performansının rijit kanata göre daha iyi olduğunu ortaya koymuşlardır. Shyy vd. [10] düşük Reynolds sayılarındaki çırpan kanat aerodinamiği ile ilgili son zamanlarda yapılan çalışmaları incelemişlerdir. Ayrıca çalışmada çırpan kanat kinematiği, korunum denklemi, ölçülendirme kuralları gibi temel konulara değinilmiştir.

Kıyak vd. [11] çalışmalarında doğrusal olmayan bir döner kanatın matematiksel modellemesini yaparak geliştirilmiş PID yapısı ile kontrol etmişlerdir. PID kontrolünün farklı motor arıza durumlarında sistem kararlılığını sağladığını tespit etmişlerdir. Nguyen vd. [12] havada asılı kalma uçuş modunu daha istikrarlı hale getirmek için iki sabit kanat ve yüksek itki üretimi için ise iki çırpan kanat olmak üzere dört kanatlı hibrit bir kanat tasarlamışlardır. 14,6 g ağırlığında ve $22 \mathrm{~cm}$ kanat açıklığına sahip olarak üretilen model 3 dakika boyunca dikey kalkış ve havada asılı kalma gibi uçuş durumlarını başarıyla gerçekleştirmiştir. Tay [13] çırpan kanatlı mikro hava araçlarının performansının kanat şekil değiştirmesiyle iyileştirilebilmesi için üç boyutlu simülasyon yöntemi kullanarak farklı şekil değiştirme formlarında çalışma yapmıştır. Çalışmasının sonucunda itki

Tablo 1. Sabit, döner ve çırpan kanatlı hava araçlarının kıyaslaması [1] (Fixed, rotary, and flapping air vehicles comparison)

\begin{tabular}{llllll}
\hline İHA Tipi & Süzülme & Karmaşıklık & Kıvraklık & Verimlilik & Fark Edilebilme \\
\hline Sabit Kanatlı & Kırmızı & Yeşil & Kırmızı & Kırmızı & Kırmızı \\
Döner Kanatlı & Yeşil & Sarı & Sarı & Sarı & Kırmızı \\
Çırpan Kanatlı & Yeşil & Kırmızı & Yeşil & Yeşil & Yeşil \\
\hline
\end{tabular}

Yeşil: En iyi performans Sarı: Orta derece performans Kırmızı: Kötü performans

(Green: Best performance Yellow: Average performance Red: Bad performance) 
için \%111 ve verimlilik için \%125'e kadar iyileştirmelerin gerçekleşebileceğini ortaya koymuştur. Goel vd. [14] farklı kanat yapılarının tasarımı ve bu yapıların ABAQUS programını kullanarak farklı irtifalardaki çeşitli aerodinamik kuvvetler altında sonlu elemanlar analizi çalışması yapmışlardır. Sai vd. [15] $40 \mathrm{~cm}$ kanat açıklığına sahip, dişli mekanizma sayesinde çırpma hareketi yapan bir mikro hava aracı tasarlayıp üretmişlerdir. Havada asılı kalma modunda yeterli taşıma üretimi sağlamak için farklı veter uzunlukları ve hücum açılarında 300'den fazla test yaparak kanadı optimize etmişlerdir. Şenol vd. [16] çırpan kanatlı dört çubuk mekanizması tasarlamışlar ve çırpan kanat hareket denklemi yardımıyla kinematik analizini yapmışlarıdır. Tasarımlarını Ansys Fluent paket programı kullanarak sayısal analiz yoluyla incelemişler daha sonra tasarımı üreterek ölçüm cihazları yardımıyla kuvvet analizini gerçekleştirmişlerdir. Sayısal analizlerde ileri itki kuvvetinin oluştuğu gözlemlenmiş, çırpma açısı ve frekansının aerodinamik kuvvetlerin oluşumunda çok büyük öneme sahip olduğu ortaya konulmuştur.

Hu vd. [17, 18], Yafeng vd. [19], Rose vd. [20], Shkarayev vd. [21, 22], Valiyff vd. [23] ile Jones vd. [24] çırpan kanatlı İHA uygulamalarında deneysel araştırmalar yapmışlardır. $\mathrm{Bu}$ çalışmalarda üretilen kanatlara çırpma hareketi yaptırılarak farklı durumlardaki taşıma ve itki kuvveti analiz edilmiştir. Nakata vd. [25] ile Anbarcı [26] kanat çırpma hareketinin aerodinamiğini incelemiştir. $\mathrm{Bu}$ çalışmalarda çırpan kanat üzerindeki akış hesaplamalı akışkanlar dinamiği kullanılarak simüle edilmiştir. Paket bir HAD programında 2 ve 3 boyutlu olarak incelenen çalışmaların deneysel sistemle beraber desteklendiğinde çırpan kanat üzerindeki daimi olmayan akış karakteristiklerini anlamada yararlı olduğu görülmüştür. Wu [27], Nguyen vd. [28] ile Kim vd. [29] yapılan deneysel çalışma için kanat aktüatör (eyleyici) mekanizması kullanmışlardır.

$\mathrm{Bu}$ çalışmalarda farklı test koşullarında taşıma ve itki kuvvetlerini ölçmek için aerodinamik ölçümler yapılmış ve uçuş dinamiği incelenmiştir. Yeo vd. [30] çalışmalarında gerçek zamanlı aerodinamik kuvvetlerin tahminini sağlamak için çırpan kanat yüzeylerine dağıtılmış basınç algılama sistemi yerleştirmişlerdir. Sonuç olarak çırpan kanatlı hava araçları veya ornitopterlerin yüksek hızlı çırpma yüzeyleri tarafından üretilen düzgün olmayan akıştan dolayı kontrolünün zor olduğunu ortaya koymuşlardır.

Grauer vd. [31] çalışmalarında bir ornitopterin çırpan kanatları tarafında üretilen itki ve taşıma kuvvetinin sonuçlarını yapısal model belirlemek için sunmuşlardır. Uçuş sırasında ornitopter görsel izleme sistemi kullanılarak ölçümler elde edilmiştir. Mazaheri vd. [32] esnek bir çırpan kanadın aerodinamik performansı araştırmışlardır. Bu amaçla, çalışmalarında çırpan kanadın değişken aerodinamik kuvvetlerini ölçmek için çırpan kanat sistemi ve deney düzeneği kurmuşlardır. Test edilecek kanat için çırpma hareketini sağlayacak mekanik bir sistem tasarlanmış ve imal edilmiştir. Öncelikle çırpma hareketi yaptırılmadan kanadın taşıma kuvveti farklı hava hızı ve hücum açılarında tespit edilmiştir. Daha sonra çırpan kanat mekanizmasına bağlanarak farklı frekanslarda taşıma ve itki kuvvetleri ölçülmüştür. Sonuç olarak çırpma frekansının arttı̆̆1 her durumda itkinin de arttığını belirlenmiştir. Hızın artması ile de taşıma kuvvetinin arttığı fakat yüksek frekanslarda bu artışın daha az olduğu görülmüştür.

Sunulan bu çalışmada ise hava araçlarında kullanılan çırpan kanatlardaki taşıma ve itki kuvveti değerlerinin farklı hava hızı, hücum açısı ve çırpma frekanslarındaki değişimi incelenmiştir. Kanatlar farklı malzemelerden üretilerek malzeme değişiminin aerodinamik parametrelere etkisi araştırılmaya çalışılmıştır. Deneysel çalışma için üretilen mekanizma ile kanatlara çırpma hareketi yaptırılarak rüzgâr tünelinde bir takım deneysel ölçümler yapılmıştır.

\section{KANAT PERFORMANS BÜYÜKLÜKLERİ (WING PERFORMANCE MAGNITUDES)}

Kanat etrafında üç yönde kuvvet ve moment bileşenleri oluşur. $\mathrm{Bu}$ bileşenler taşıma (L), sürükleme (D) ve yanlamasina kuvvetler (Y) ile yalpa (Mx), yunuslama (My) ve sapma $(\mathrm{Mz})$ momentleridir. Şekil 1'de bu bileşenler bir kanat üstünde ayrıntılı olarak gösterilmiştir. Kanat performans incelemelerinde bu bileşenlerden taşıma ve sürükleme kuvveti ile yunuslama momenti incelenmektedir.

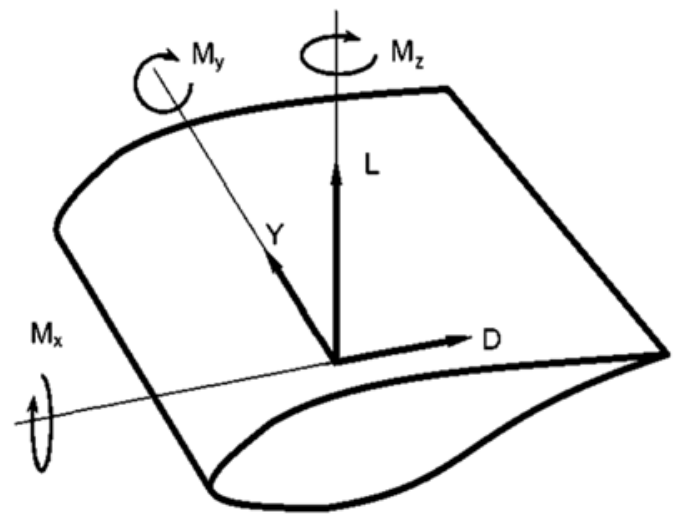

Sekil 1. Kanat üzerinde kuvvet ve momentler [33] (Forces and moments on airfoil)

Kanat profilleri farklı şekil ve boyutlara sahiptir. Bunun sonucu olarak kanat profillerinin avantaj ve dezavantajlarını değerlendirirken boyutsuz katsayılar dikkate alınmalıdır [33]. Taşıma ve sürükleme katsayıları olan boyutsuz katsayılar, Eş. 1 ve Eş. 2'de iki boyutlu olarak ifade edilmektedir.

Taşıma Katsayısı:

$\mathrm{C}_{\mathrm{L}}=\frac{2 \mathrm{~L}}{\rho \mathrm{V}^{2} \mathrm{c}}$

Sürükleme Katsayısı:

$C_{D}=\frac{2 D}{\rho V^{2} c}$ 


\section{3. ÇIRPAN KANAT KINEMATİĞI (FLAPPING WING KINEMATICS)}

Çırpan kanatlı yapıların en önemli özelliği taşıma ve itki kuvvetinin kanat tarafından sağlanmış olmasıdır. İtki kuvveti kanatlara yaptırılan çırpma hareketi sonucunda oluşmaktadır [34]. Bu çalışmada kullanılan kanatlara çırpma hareketi, Mazaheri ve Ebrahimi'nin çalışmalarında kullandığı dört çubuklu mekanik bağlantı olarak yer alan bir mekanizma ile sağlanmıştır. $\mathrm{Bu}$ mekanizma elektrik motorundan aldığ 1 dönü hareketini çırpma hareketine çevirmektedir. Şekil 2'de görüldüğü gibi her bir döngüde krank $\left(r_{2}\right) 360^{\circ}$ döner ve $r_{4}$ bir genlik açısıyla salınım yapar. Kanat çırpma mekanizmasına $r_{4}$ kısmından bağlanır. Her bir düğüm yerine $r$ tanımlayarak ve kompleks (karmaşık) değişkenler dizisini kullanarak Eş. 3 bağıntısı yazılabilir:

$r_{2} e^{j \theta_{2}}+r_{3} e^{j \theta_{3}}=r_{1} e^{j \theta_{1}}+r_{4} e^{j \theta_{4}}$

Hız ve ivme denklemleri yukarıdaki denklemin birinci ve ikinci zaman türevleri alınarak Eş. 4 ve Eş. 5 edilebilir.

$\left[\begin{array}{cc}r_{3} \cos \theta_{3} & -r_{4} \cos \theta_{4} \\ -r_{3} \sin \theta_{3} & r_{4} \sin \theta_{4}\end{array}\right]\left\{\begin{array}{l}\omega_{3} \\ \omega_{4}\end{array}\right\}=\left\{\begin{array}{c}-r_{2} \omega_{2} \cos \theta_{2} \\ r_{2} \omega_{2} \sin \theta_{2}\end{array}\right\}$

$\left[\begin{array}{cc}r_{3} \cos \theta_{3} & -r_{4} \cos \theta_{4} \\ -r_{3} \sin \theta_{3} & r_{4} \sin \theta_{4}\end{array}\right]\left\{\begin{array}{l}\beta_{3} \\ \beta_{4}\end{array}\right\}=$

$\left\{\begin{array}{l}-r_{2} \beta_{2} \cos \theta_{2}+r_{2} \omega_{2}^{2} \sin \theta_{2}+r_{3} \omega_{3}^{2} \sin \theta_{3}-r_{4} \omega_{4}^{2} \sin \theta_{4} \\ -r_{4} \omega_{4}^{2} \cos \theta_{4}+r_{3} \omega_{3}^{2} \cos \theta_{3}+r_{2} \omega_{2}^{2} \cos \theta_{2}+r_{2} \beta_{2} \sin \theta_{2}\end{array}\right\}$
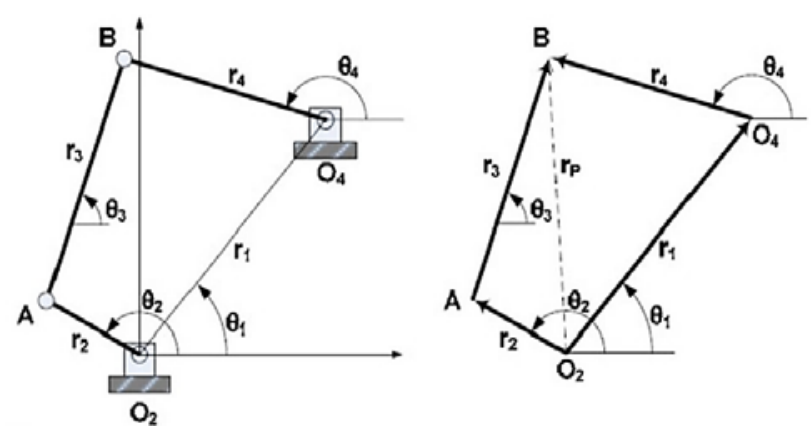

Şekil 2. Dört çubuklu mekanik bağlantının şematik gösterimi [34]

(Schematic of the four-bar mechanical linkage)

Çırpan kanat mekanizmasının kinematik analizi yukarıda yer alan denklem setine göre yapılmıştır. Tasarımı yapılan çizimde bağlantılar için değerler şu şekildedir:

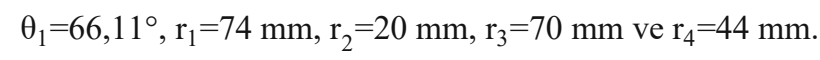

\section{ORNITHOPTER KANATLARIN ÖZELLİKLERİ (SPECIFICATIONS OF ORNITOPTER WINGS)}

Deneysel çalışmada kullanılan kanatlar Mazaheri vd. [34] çalışmalarında yer alan ve piyasada bulunan iki başarılı ornitopterden biri olan Cybird P1 adlı çırpan kanata göre ölçeklendirilip, üretilmiştir. Üretilen kanatlar bir kompozit 1038 mil yardımı ile kuvvet ve moment ölçüm sistemine (yük hücresi) entegre edilerek kuvvet değerleri ölçülmüştür. Çırpan kanatlı hava araçları normal uçuş şartlarında kanatlarını saniyede en az 3-6 kez çırparlar ve hızları 30 $\mathrm{km} / \mathrm{sa}$ 'i bulabilir. Bu sebeple kanat yapıları çok önemli bir kısmı oluşturmaktadır. Kanat iskeleti ve esnek kanat yapısı kuş, yarasa gibi uçan canlılardan esinlenerek üretilmektedir. Kanat yapısı genellikle; karbon fiber kirişlerden ve bir ă̆ gibi gerilen naylondan oluşmaktadır. Deneylerde üç farklı malzeme kullanılmıştır. Tablo 2'de çırpan kanadın parametreleri ve Şekil 3'te deneylerde kullanılan kanadın 2 boyutlu çizimi gösterilmiştir.

Tablo 2. Çırpan kanadın özellikleri (Specifications of flapping wing)

\begin{tabular}{ll}
\hline Parametre & Değer veya Karşılığ1 \\
\hline Kanat genişliği (mm) & 340 \\
Açıklık oranı & 2 \\
Yukarı doğru hareket & 30 (yatay düzlem ile) \\
(derece) & 20 (yatay düzlem ile) \\
Aşağ1 doğru hareket (derece) & $0-5$ \\
Çırpma frekansı (Hz) & DC Motor ve Güç \\
Tahrik sistemi ve enerjisi & Kaynağ1 \\
\hline
\end{tabular}

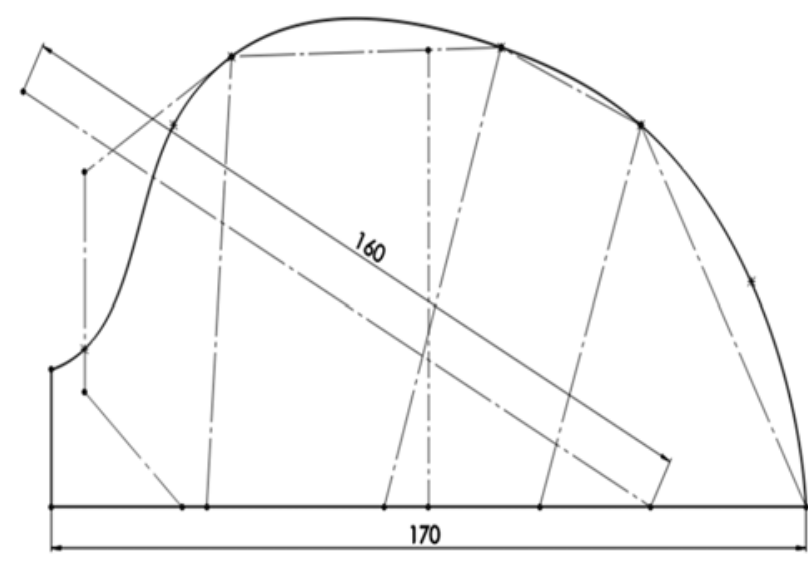

Şekil 3. Çırpan kanadın 2 boyutlu görünümü (2D view of flapping wing)

\section{DENEY SİSTEMİ (EXPERIMENTAL SYSTEM)}

\subsection{Ses Altı Rüzgâr Tüneli (Subsonic Wind Tunnel)}

Deneysel çalışmalar emmeli açık çevrimli tip rüzgâr tünelinde gerçekleştirilmiştir. Rüzgar tüneli 6,1 daralma oranı ve $0,57 \mathrm{~m} \times 0,57 \mathrm{~m}$ test bölgesi giriş boyutlarına sahiptir. Test odası uzunluğu $1.8 \mathrm{~m}$, tünelin çalışma hızı 3 $\mathrm{m} / \mathrm{s}-33 \mathrm{~m} / \mathrm{s}$ aralığındadır. Tünelde kullanılan motorun gücü $15 \mathrm{~kW}$, devir say1s1 ise $150 \mathrm{devir} / \mathrm{min}$ - $1200 \mathrm{devir} / \mathrm{min}$ aralığında frekans invertörü ile harici olarak kontrol edilmekte ve istenilen çalışma hızı ayarlanmaktadır. Tünelin test odasının sağ ve sol tarafa $62 \mathrm{~cm}$ genişliğinde ardışık iki kapak konulmuş olup akış görüntüleme deneyleri için geniş bir açık alan bırakılmıştır. Şekil 4'te rüzgâr tünelinin test bölgesi, giriş ve tahliye tarafları gösterilmiştir. 


\subsection{Sicak Tel Anemometresi (Hot-wire Anemometer)}

Deneylerde hız ölçümleri sıcak tel anemometresi ile yapılmıştır. Kullanılan cihaz Dantec Dynamics firmasına ait yüksek hassasiyetli "Sicak Tel" sistemidir. Sistem otomatik kalibrasyon ünitesine ve yüksek frekanslı 1, 2 ve 3 boyutlu noktasal hız-sıcaklık ölçümü yapabilme özelliğine sahiptir. Özellikle, tek noktadaki çok hızlı akış hızı değişimleri için ideal bir çözümdür. Sistemde hız, sabit tel sıcaklı̆̆1 prensibiyle ölçülür. Tel bir devre ile isitılır. Telin üzerinden geçen akış telde 1sı kaybına yol açar ve telin sıcaklığını dengeleyen Wheatstone köprüsündeki güç tüketiminin ölçüsü, telin üzerinden geçen akışın hızını verir. Rüzgar tünelimizin x yönündeki türbülans şiddetinin serbest akış hızı ile değişimleri Şekil 5'te verilmiştir. Bu şekilden de görüldügü gibi türbülans şiddeti değerleri \%1'nin altındadır. Dolayısıyla Rüzgar tünelinin türbülans seviyelerinin uluslararası kabul gören seviyelerin altında olduğu görülmektedir.

\subsection{Kuvvet ve Moment Ölçüm Sistemi ve Döndürme Ünitesi (Force and Torque Measurement System and Rotary Unit)}

Kuvvet ve moment ölçüm sistemi Gamma (6 bileşenli SI-322,5 modeli) tipi bir yük hücresi (loadcell)'dir. Yük hücresi z ekseninde $100 \mathrm{~N}$, x ve y ekseninde ise $32 \mathrm{~N}$ maksimum ölçüm üst sınırına sahiptir. Ayrıca üç yöndeki maksimum moment ölçüm değerleri ise 2,5 Nm'dir. Ölçüm çözünürlükleri bileşenlere göre değişmekle beraber veri toplama sistemi 16 bittir. Yük hücresi ve aparatları Şekil 6'da ayrıntılı olarak gösterilmiştir. Bu sistem kanat çırpma anında oluşan itki ve taşıma kuvvetlerini ölçmede kullanılmıştır. Yük hücresi gerilme ölçer (strain gauge) tellerin birbirine Wheatstone köprüsü şeklinde bağlantılı halidir. $\mathrm{Bu}$ tellerde uzunluk değişince (uzama veya sıkıştırılma) direnci değişimi ölçülerek yük hücresi üzerindeki yükü belirlenir. Rüzgâr tünelinde analizleri yapılan deney numunelerinin kuvvetleri ve momentleri hızlı ve güvenilir bir şekilde bu sistem ile ölçülmüştür.

\section{4. Çırpan Kanat Mekanizması (Flapping Wing Mechanism)}

Bağlantı şekilleri, dişli mekanizmaları ve kanat yapıları farklı olmakla beraber çırpan kanatlı hava araçlarında temel sistem parçaları; DC motor, batarya, dişli mekanizması, bağlantı rotları ve kanatlardır. Bu çalışmada ise batarya yerine harici güç kaynağı kullanılmıştır. İki kademeli dişli mekanizması farklı ölçülerdeki dişlilerden oluşmakta ve dişli tahvil oranı her iki kademe içinde 5:1'dir. DC motor maksimum güçte 15000 devir/min hızla dönebilmekte ve
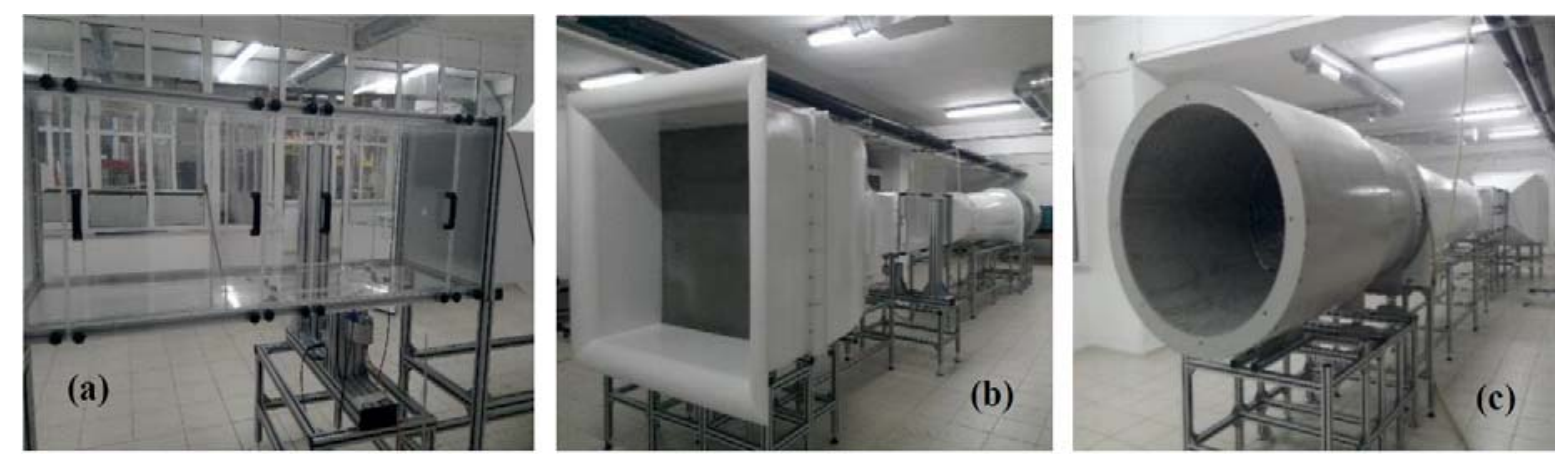

Şekil 4. Deneyde kullanılan rüzgar tüneli a) Test bölgesi b) Emme tarafı c) Tahliye tarafı (Wind Tunnel a) Test section b) Suction side c) Discharge side)

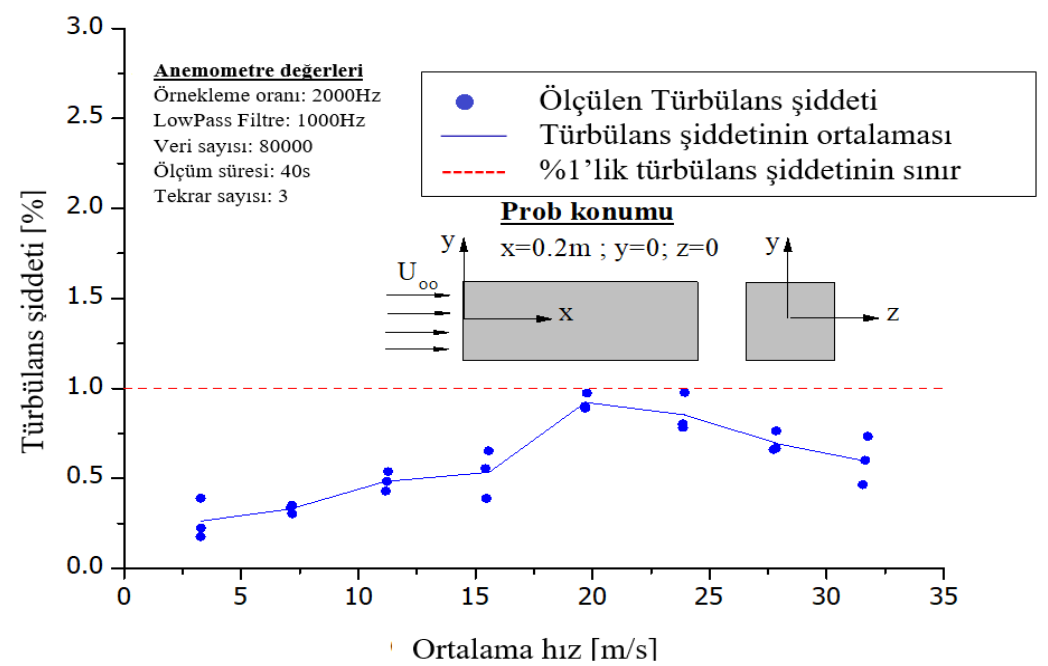

Şekil 5. Rüzgar tünelinin türbülans şiddetinin serbest akış hızı ile değişim grafiği (Graph of turbulence intensity with free flow speed) 
dişliler DC motordan aldı̆̆ elemanları yardımı ile kanatlarda çırpma hareketine dönüştürmektedir. Dişliler ile kanatlar arasındaki bağlantı rotunun açısı ve uzunluğu belirlenerek çırpma genliği olarak adlandırılan açı optimum şekilde ayarlanmıştır. Literatüre uygun olacak şekilde çırpma genliği +30 derece ile -20 derece olarak mekanizma tasarlanmıştır. $\mathrm{Bu}$ çalışmada kanada çırpma hareketi yaptıracak mekanizma Cybird P1 ornitopter modeline göre uyarlanmıştır [34, 35].

Dişli mekanizmasının çizimleri SolidWorks programında yapılmıştır. Tasarlanan çırpan kanat mekanizması çizimi Şekil 7'de ve üretilen mekanizmanın önden ve yandan görüntüsü Şekil 8'de verilmiştir.

\subsection{Deneysel Ölçüm Hatası (Experimental Measurement Error)}

Deneysel çalışmalardaki hata ve belirsizlikler ölçüm aletinin seçiminden, özelliklerinden, kalibrasyonundan, çevre ve deney şartlarından ve okuma özelliklerinden kaynaklanmaktadır. Deneysel çalışmalarda yapılan hatalar, araştırmacı tarafından yapılan hatalar haricinde iki tiptir. Bu hataların ilki sabit veya sistematik hatalar, diğeri ise düzensiz hatalardır. Sabit hata kalibrasyon veya düzeltme ile ortadan kaldırılabilmekte fakat düzensiz hatalar rastgele oluştukları için ortadan kaldırılamamaktadır. Belirsizlik analizi, deneysel sonuçlardaki bu rastgele hataların belirlenmesi temeline dayanmaktadir [36].

Bu çalışma kapsamında rüzgâr tünelinde yapılan deneylerdeki belirsizlik analizi Holman tarafindan sunulan yöntemle hesaplanmıştır.

- Ortalama serbest akım hızı ölçümünden kaynaklanan belirsizlik $\mathrm{u}_{\mathrm{U} \infty}=\% \pm 0,8$

- Modelin kenar uzunluğundan kaynaklanan belirsizlik $\mathrm{u}_{\mathrm{L}}=\% \pm 2,0$

- Havanın kinematik viskozitesinden kaynaklanan belirsizlik $\mathrm{u}_{v}=\% \pm 0,6$

Gama tipi yük hücresi saniyede 1000 adet veri ölçmektedir. Her 20 adet verinin ortalamasını alarak her saniye için 50 veri oluşturmaktadır.

- Ortalama oluşan standart sapma yaklaşık $=\% \pm 2,857$ Newton
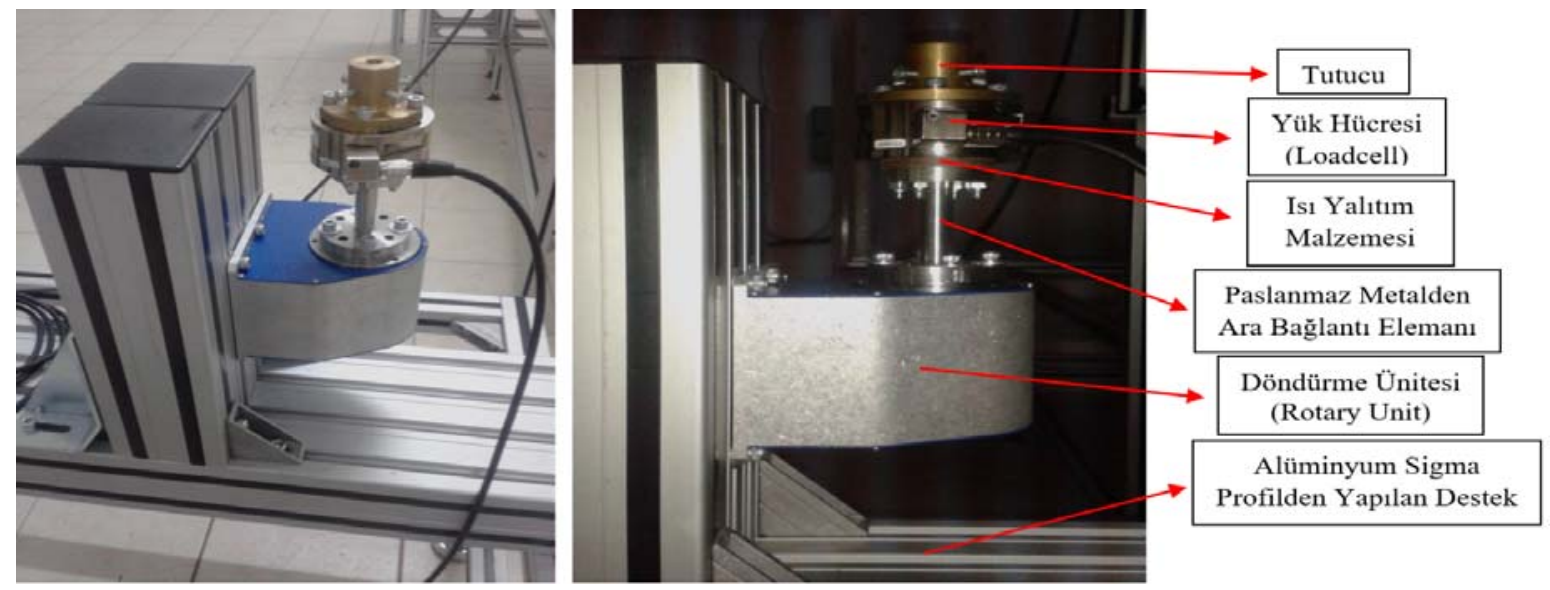

Şekil 6. Yük hücresi ve aparatları (The loadcell and apparatus)

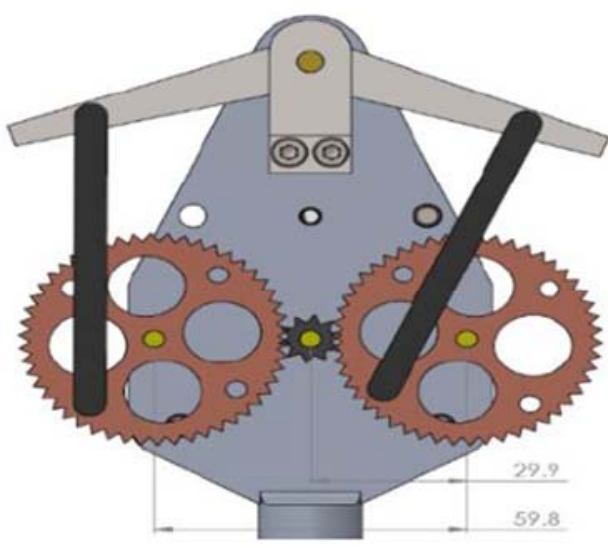

(a)

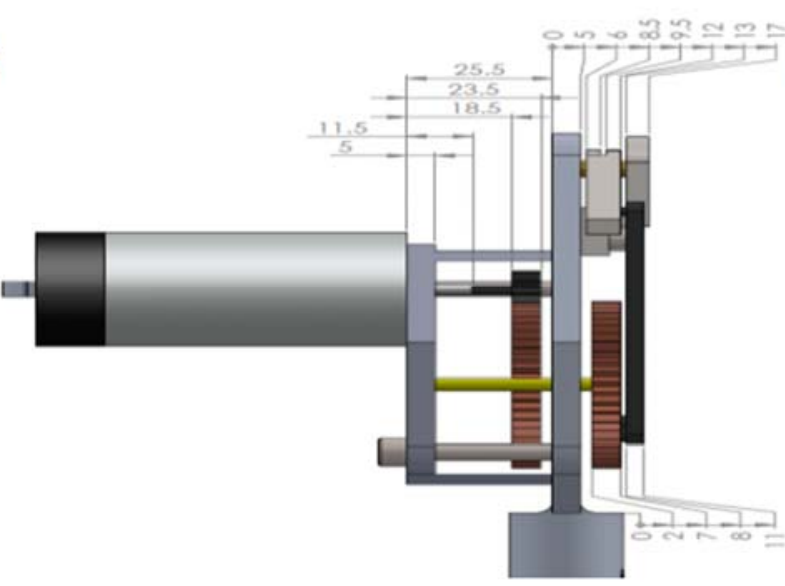

Şekil 7. Çırpan kanat mekanizması çizimleri a) Ön görünümü b) Yan görünümü (Flapping Wing Mechanism drawings a) Front view b) Side view) 
Yukarıda verilen değerlere göre Reynolds sayısı için hesaplanmış oluşabilecek belirsizlik değeri aşağıda sunulmuştur.

$\mathrm{u}_{\mathrm{Re}}=\left[(0,8)^{2}+(2,0)^{2}+((-1) 0,6)^{2}\right]^{1 / 2} \quad \mathrm{u}_{\mathrm{Re}} \cong 2,236$

\subsection{Deney Düzeneği (Experimental Setup)}

Deney düzeneği çırpan kanat mekanizması, sıcak tel anemometresi, yük hücresi ve rüzgâr tünelinden oluşmaktadır. Şekil 9'da bütün halde deney düzeneği gösterilmiştir. Deney düzeneğinde bütün değişkenler elektronik olarak kontrol edilmektedir. İlk olarak sicak tel anemometresinin prob kalibrasyonları yapılmakta daha sonra yük hücresine bağlanan çırpan kanat mekanizması DC güç kaynağı ile istenilen çırpma frekansına ayarlanmaktadır. Son olarak frekans invertörü ile rüzgâr tünelinde çalışma için gerekli akış hızı ayarlanmaktadır. Yük hücresi çırpma esnasında oluşan taşıma, itki ve yanal kuvvetleri ve bu kuvvetlerin momentlerini ölçmektedir. İlk olarak, ölçüleri verilen ve üç farklı malzemeden üretilen kanatların çırpma hareketi yapılmaksızın taşıma kuvveti değerleri ölçülmüştür. Deney sirasında kanatlar rüzgar tüneline yatay olarak
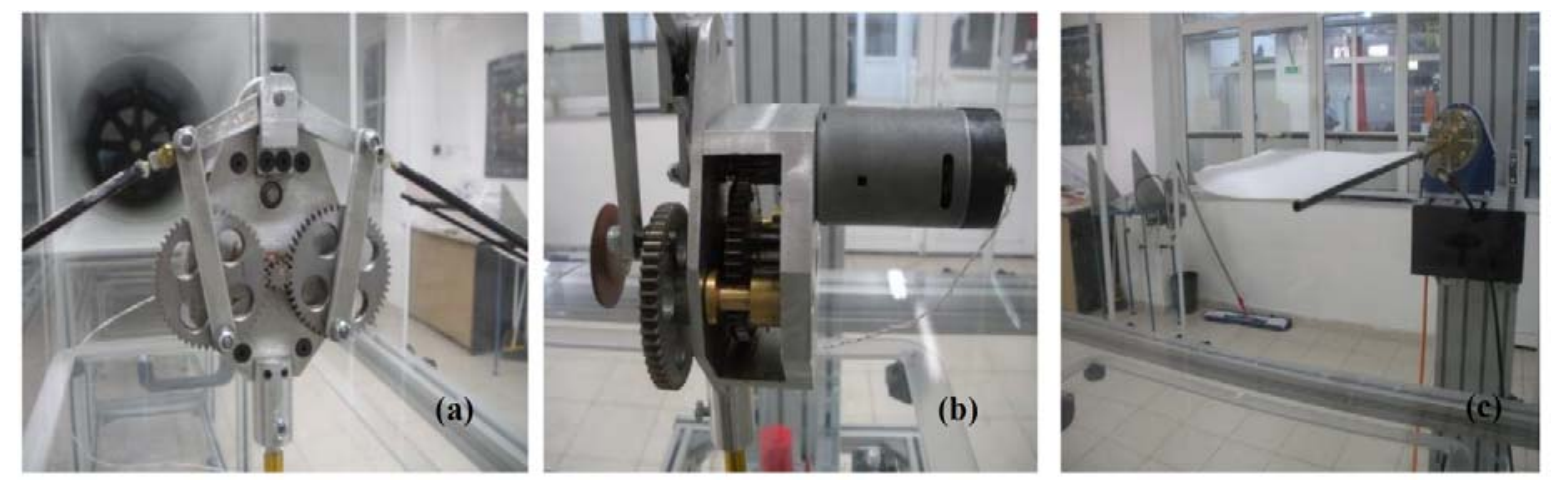

Şekil 8. Çırpan kanat mekanizması a) Önden b) Yandan görünümü c) Sabit kanadın yük hücresine bağlı hali (Flapping Wing Mechanism a) Front view b) Side view c) Situation of assembled fixed wing with Load cell)

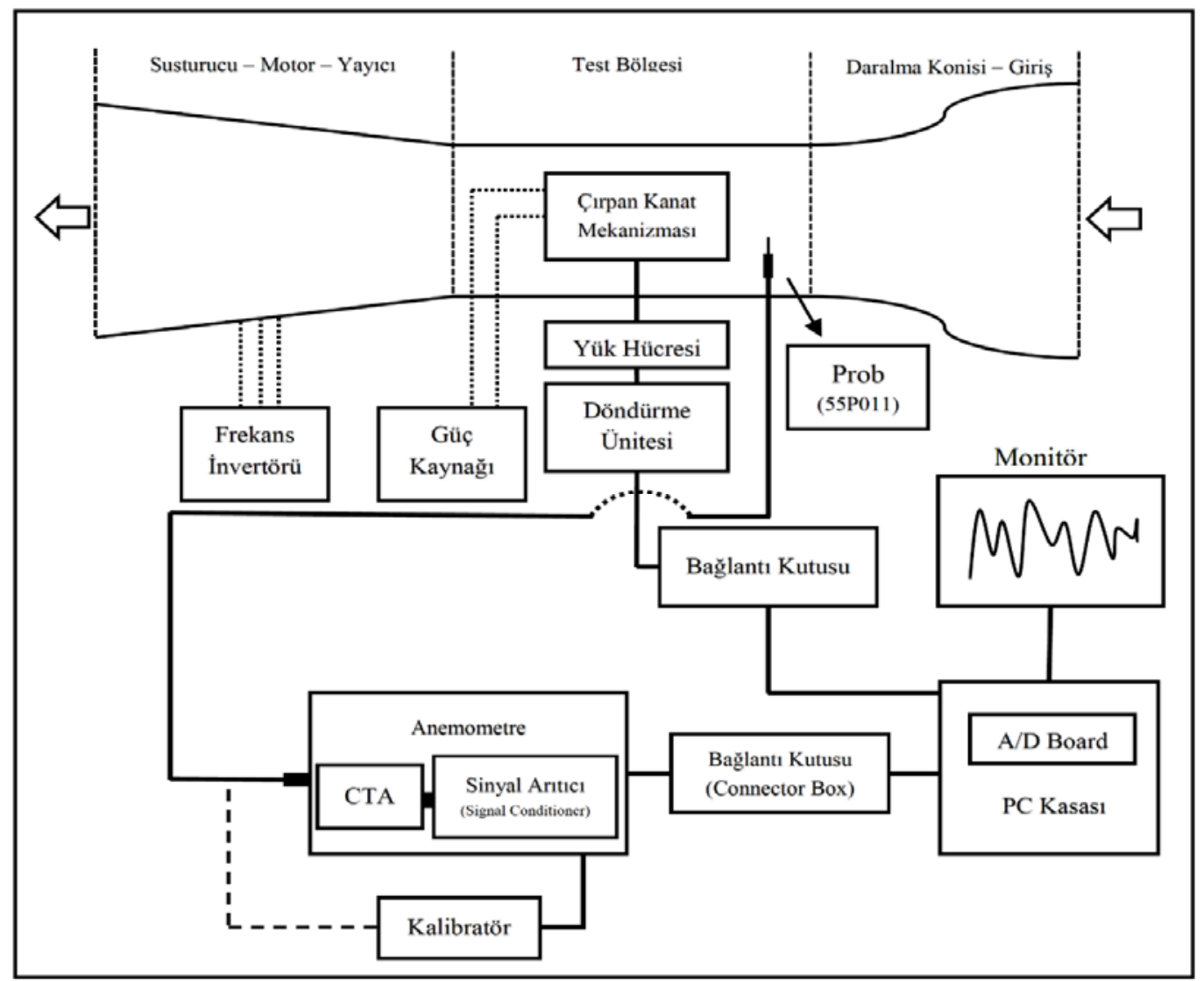

Şekil 9. Deney düzeneğinin şematik gösterimi (Schematic representation of the experimental setup) 
bağlanmıştır. Ölçümler Re sayısının 67000 - 134000 aralığında değişen hız değerleri ve $5^{\circ}, 10^{\circ}, 15^{\circ}$ ve $20^{\circ}$ hücum açılarında yapılmıştır. Literatürde yer alan naylon kanat modeline göre üretilen kanatlar rüzgar tüneli boyutuna göre küçültülüp, ölçeklendirilmiştir. Çırpan kanat düzeneğine bağlanan ölçeklenmiş Cybird P1 kanat modelinin rüzgâr tüneli içerisindeki hava hızı, çırpma frekansı ve hücum açıları değiştirilerek elde edilen taşıma ve itki kuvveti değerleri ölçülmüştür. Ölçümler sabit kanat deneylerindeki şartlar için $6,8,10$ ve $12 \mathrm{~m} / \mathrm{s}$ hava hızlarında ve $0^{\circ}, 5^{\circ}, 10^{\circ}$, $15^{\circ}$ ve $20^{\circ}$ hücum açılarında yapılmıştır. Bununla birlikte çırpma frekansı, kanadın saniyedeki çırpma sayısı, değiştirilerek taşıma ve itki kuvvetine etkisi incelenmiştir. Çalışma kapsamında kullanılan frekans değerleri literatüre uygun olacak şekilde; 2, 3, 3,5, 4 ve 5 Hz'dir. $5 \mathrm{~Hz}$ 'den yüksek çırpma frekanslarında oluşan moment değerlerinin kuvvet ölçüm sisteminin ölçüm kapasitesini aşması sebebi ile 5 Hz'den daha büyük frekanslarda ölçüm yapılamamıştır.

\section{SONUÇLAR VE TARTISYMALAR (RESULTS AND DISCUSSIONS)}

İlk olarak üç farklı malzemeden üretilen kanatların çırpma hareketi yapılmaksızın taşıma kuvveti değerleri ölçülmüştür. Deney sırasında kanatlar rüzgâr tüneline yatay olarak bağlanmıştır. Ölçümler Re sayısının 67000 - 134000 aralığında değişen hız değerleri ve $5^{\circ}, 10^{\circ}, 15^{\circ}$ ve $20^{\circ}$ hücum açılarında yapılmıştır. Şekil 10'da literatürde yer alan naylon kanat modelinin taşıma kuvveti değerleri ile bu çalışmada rüzgâr tünelinde ölçümleri yapılan naylon kanadın değerleri karşılaştırılmıştır.

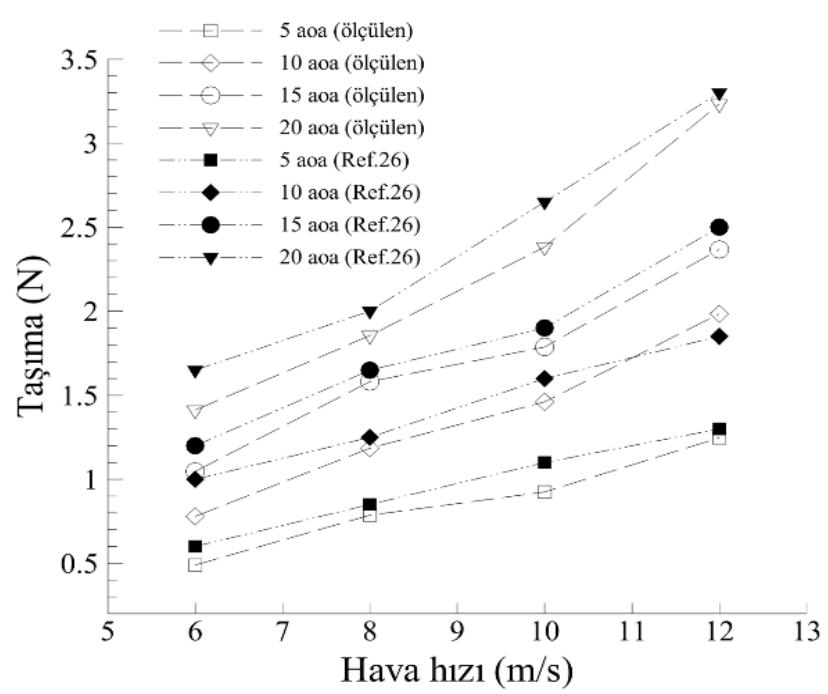

Şekil 10. Naylon kanat için deneylerin literatürle karşılaştırılması

(Comparison of experiment and literature for nylon wing)

Rüzgâr tünelinde ölçülen taşıma kuvveti değerleriyle literatürdeki değerlerin birbirine yakın olduğu
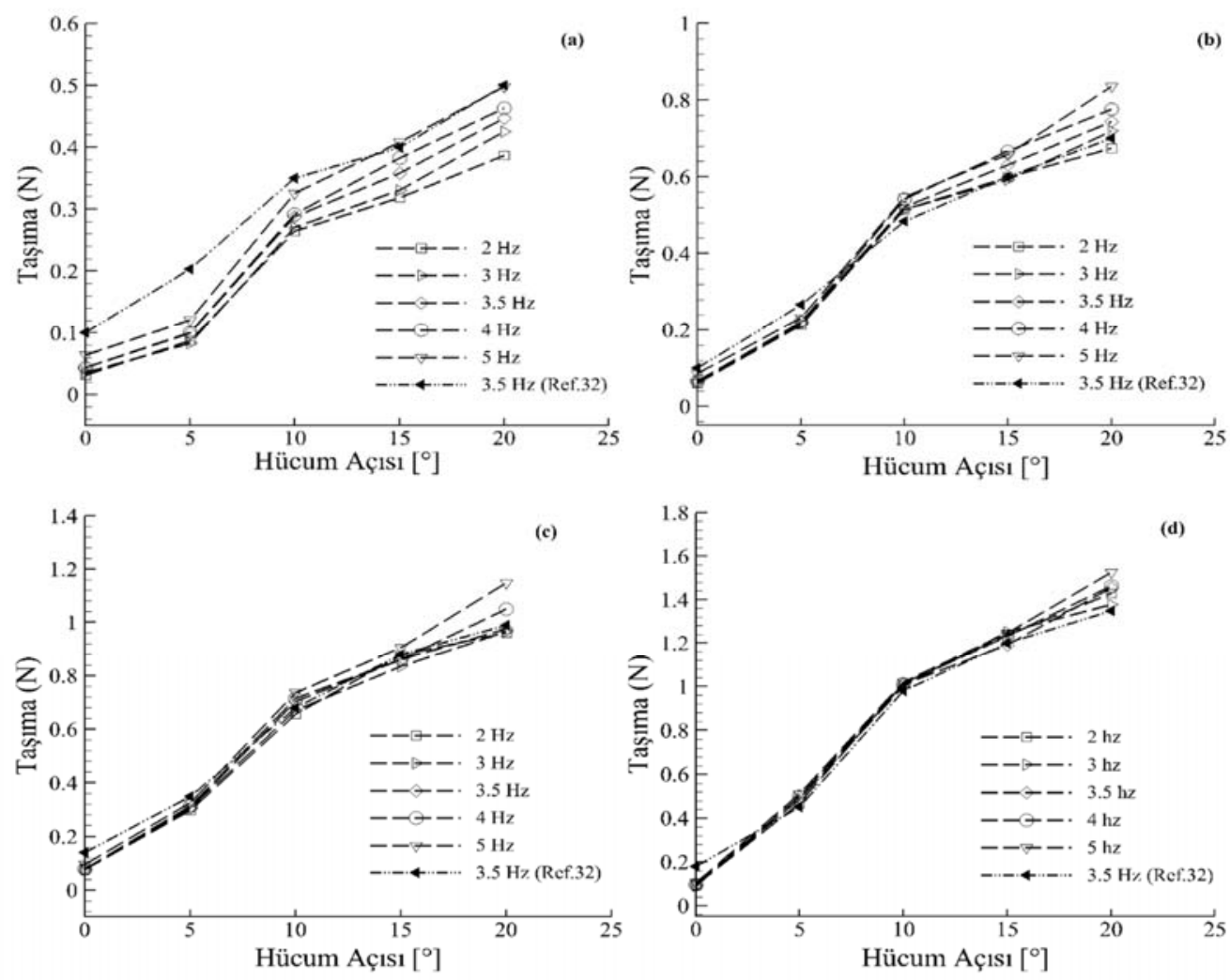

Şekil 11. Hücum açısının naylon kanadın taşıma kuvveti üzerine etkisi (Effect of attack angle on lift forces of nylon wing) a) $\mathrm{V}=6 \mathrm{~m} / \mathrm{s} \mathrm{b}$ ) V= $8 \mathrm{~m} / \mathrm{s} \mathrm{c}$ ) V=10 m/s d) V=12 m/s 
gözlemlenmiştir. Hücum açısının $5^{\circ}$ 'den $20^{\circ}$ 'ye kadar artması ile birlikte taşıma kuvveti önemli ölçüde artmaktadır. Ayrıca rüzgâr tünelindeki hava hızının artması da taşıma kuvvetini artıran diğer bir faktör olarak görülmektedir. İkinci olarak çırpan kanat düzeneğine bağlanan farklı kanatların rüzgâr tüneli içerisindeki hava hızı, çırpma frekansı ve hücum açıları değiştirilerek elde edilen taşıma ve itki kuvveti değerleri ölçülmüştür. Ölçümler sabit kanat deneylerindeki şartlar için $6,8,10$ ve $12 \mathrm{~m} / \mathrm{s}$ hava hızlarında ve $0^{\circ}, 5^{\circ}, 10^{\circ}$, $15^{\circ}$ ve $20^{\circ}$ hücum açılarında yapılmıştır. Çırpma frekansı değiştirilerek taşıma ve itki kuvvetine etkisi incelenmiştir. Deneylerde kullanılan frekans değerleri; 2, 3, 3,5, 4 ve 5 Hz'dir. Şekil 11 'de naylon kanadın taşıma kuvveti değerinin hücum açılarına göre değişimleri, aynı kanadın kullanıldığ 3,5 Hz çırpma frekans için Mazaheri vd. [32] çalışması ile karşılaştırmalı olarak verilmiştir. Deneysel sonuçların Mazaheri vd. [32] çalışması ile uyumlu olduğu görülmektedir.

Şekil 12-13'de çırpma hareketi yaptırılan lateks ve ahşap kanat için taşıma kuvvetinin hücum açısıyla değişimi gösterilmiştir. Dört farklı hava hızında gerçekleştirilen ölçümlerde naylon kanatta olduğu gibi hücum açısı ile taşıma kuvveti de artmıştır. Frekans değişimi taşıma kuvvetini artırmakla birlikte hava hızı kadar etkili olmadığ görülmektedir. Çırpan kanatlı mikro hava araçlarının en önemli avantaj1 ileri doğru uçuş için gerekli olan itki kuvvetinin kanatların çırpma hareketi sonucu oluşması, ek bir güç ünitesine ihtiyaç duymamasıdır. Dişli mekanizması, DC motor ve diğer elemanlardan oluşan düzenekle çırpma hareketini sağlayan kanat üzerinde sürtünme kuvvetinin tersi yönünde bir kuvvet olan itki kuvveti oluşur. Şekil 14-17'de farklı çırpma frekansları, hücum açıları ve hava hızlarındaki itki kuvvetinin değişimi gösterilmektedir. Burada belirtilen itki kuvveti ifadesi aslında kanatlarda ölçülen sürtünme kuvvetidir [32]. Şekil 14'te üç farklı malzemeden üretilen kanatların rüzgâr hızı olmadan ölçülen itki kuvveti değerlerinin farklı frekans ve hücum açılarındaki değişimi gösterilmiştir. Rüzgâr hızı olmadan sadece çırpma hareketi yapılan durumda sürtünme kuvveti çok az olduğu için pozitif bir itki kuvveti oluşmaktadır. İtki kuvveti değerinin çırpma frekansının artması ile arttığı görülmektedir. Frekanstaki artış ise güç tüketimini aynı oranda artırmaktadır. Ayrıca hücum açısının artması ile birlikte itki kuvvetinin azaldığı gözlemlenmiştir. Şekil 15' da rüzgâr hızının 12 m/s'ye çıktığ1 durumlarda itki kuvveti değerinin diğer hava hızlarına göre daha fazla azaldığı açıkça görülmektedir.

Genel olarak çırpma frekansının artmasıyla naylon kanadın itki kuvveti artmıştır. Hava hızı ise ters orantılı olarak itki kuvvetini azalttığı tespit edilmiştir. Şekil 16'da ise farklı hücum açılarının verildiği grafiklerde çırpma frekansının itki kuvvetine olan etkisi gösterilmiştir. Çırpma frekansının artmasıyla lateks kanadın itki kuvveti artmıştır. Hava hızının $6 \mathrm{~m} / \mathrm{s}$ 'den $12 \mathrm{~m} / \mathrm{s}$ 'ye doğru artışında ise itki kuvvetinin azaldığı tespit edilmiştir.
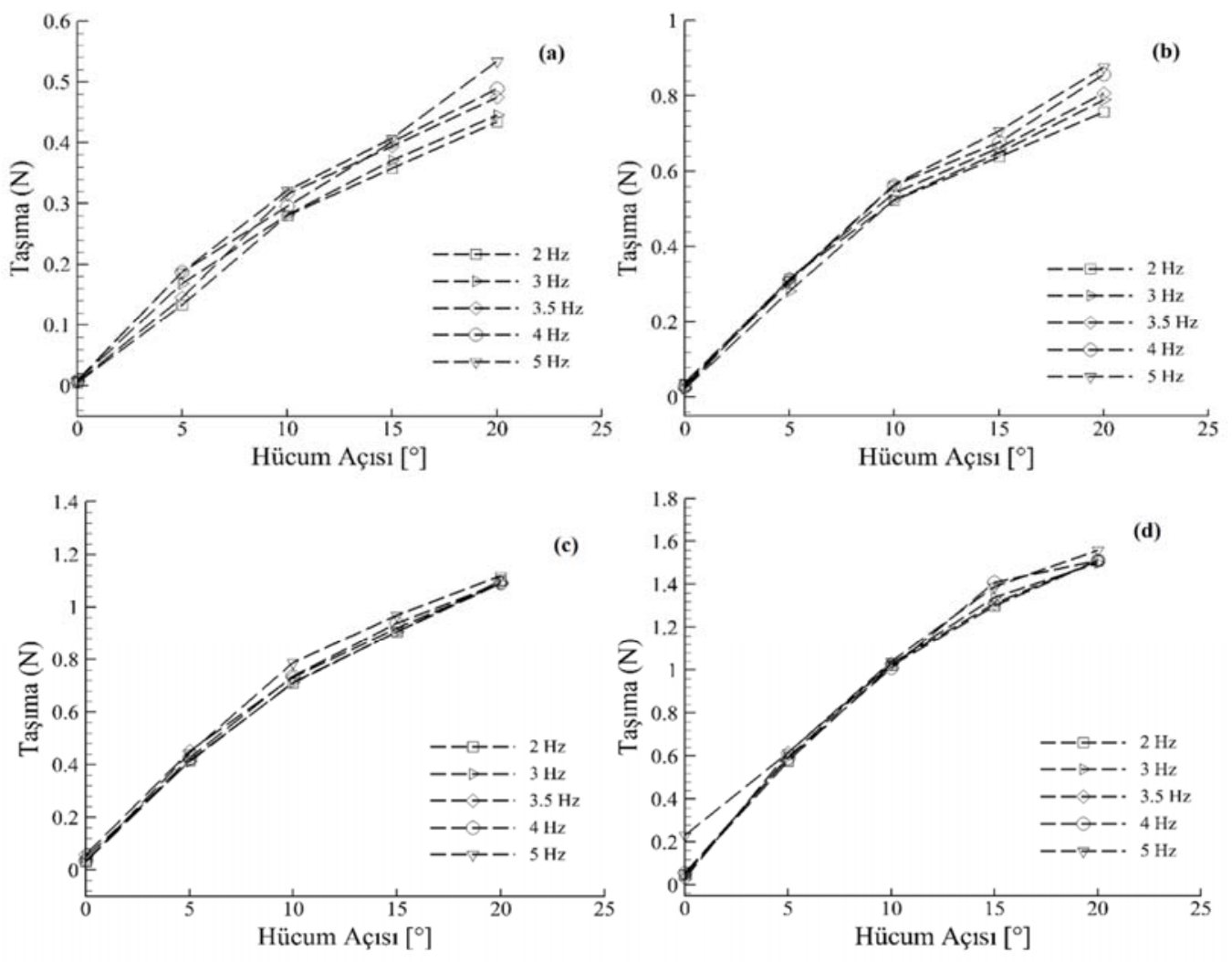

Şekil 12. Hücum açısının lateks kanadın taşıma kuvveti üzerine etkisi (Effect of attack angle on lift forces of latex wing) a) $\mathrm{V}=6 \mathrm{~m} / \mathrm{s}$ b) $\mathrm{V}=8 \mathrm{~m} / \mathrm{s} \mathrm{c}$ ) V=10 $\mathrm{m} / \mathrm{s} \mathrm{d}$ ) V=12 $\mathrm{m} / \mathrm{s}$ 

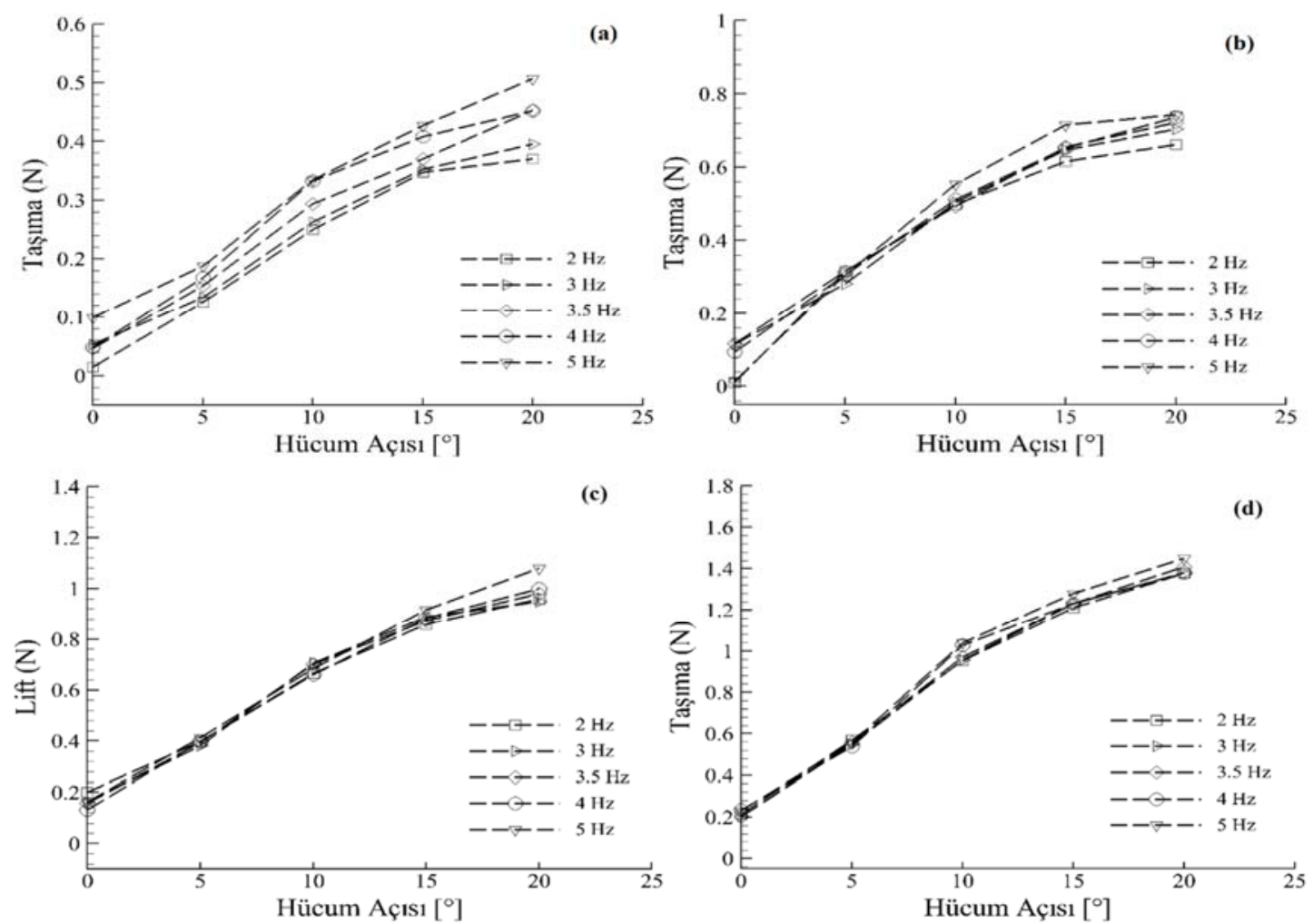

Şekil 13. Hücum açısının ahşap kanadın taşıma kuvveti üzerine etkisi (Effect of attack angle on lift forces of wood wing) a) $\mathrm{V}=6 \mathrm{~m} / \mathrm{s}$ b) $\mathrm{V}=8 \mathrm{~m} / \mathrm{s}$ c) $\mathrm{V}=10 \mathrm{~m} / \mathrm{s} \mathrm{d}$ ) $\mathrm{V}=12 \mathrm{~m} / \mathrm{s}$
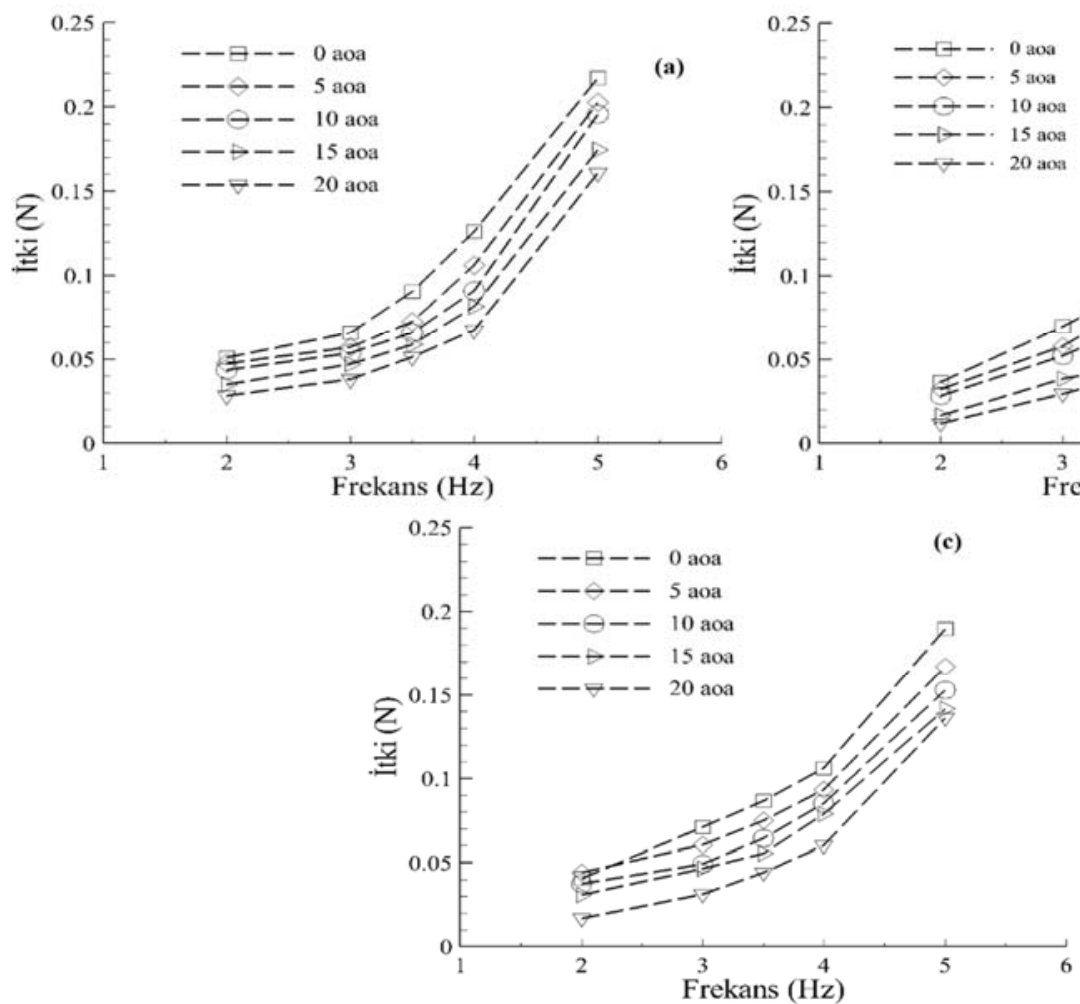

Şekil 14. Farklı çırpma frekanslarının itki kuvvetine etkisi a) Naylon b) Ahşap c) Lateks (Effect of different flapping frequencies on thrust forces a) Nylon b) Wood c) Latex)

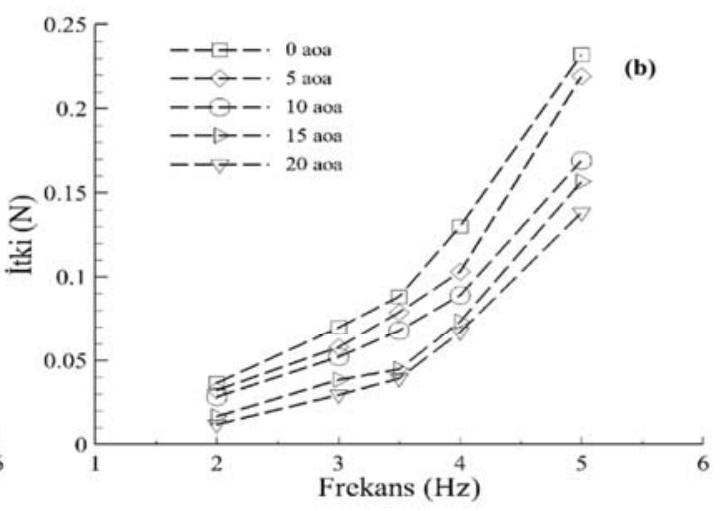

(c) 
Y1lmaz ve ark. / Journal of the Faculty of Engineering and Architecture of Gazi University 32:4 (2017) 1035-1050
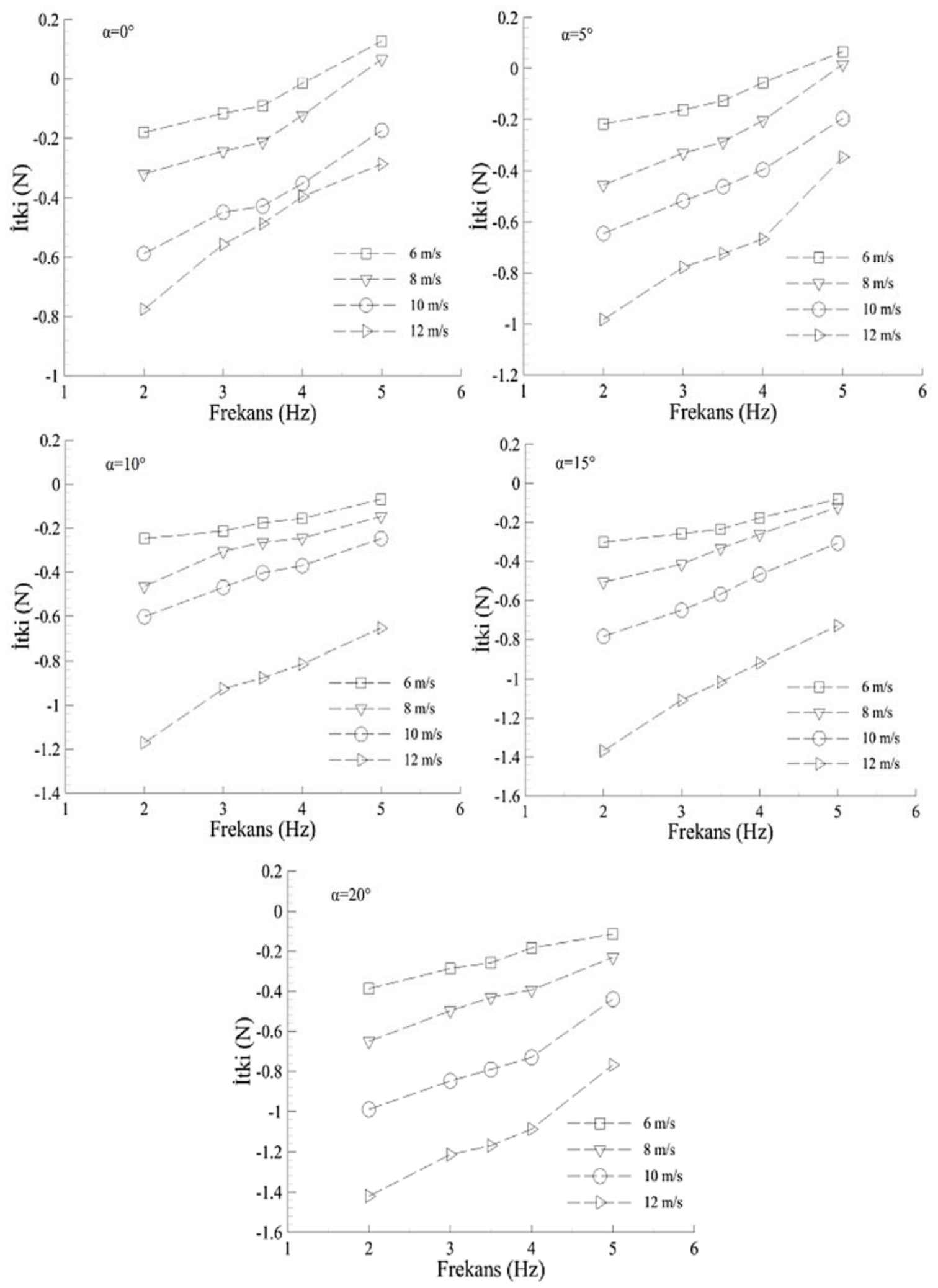

Şekil 15. Naylon kanadın itki kuvvetinin çırpma frekansı ile değişimi (Flapping frequencies and thrust forces for nylon wing) 
Yılmaz ve ark. / Journal of the Faculty of Engineering and Architecture of Gazi University 32:4 (2017) 1035-1050
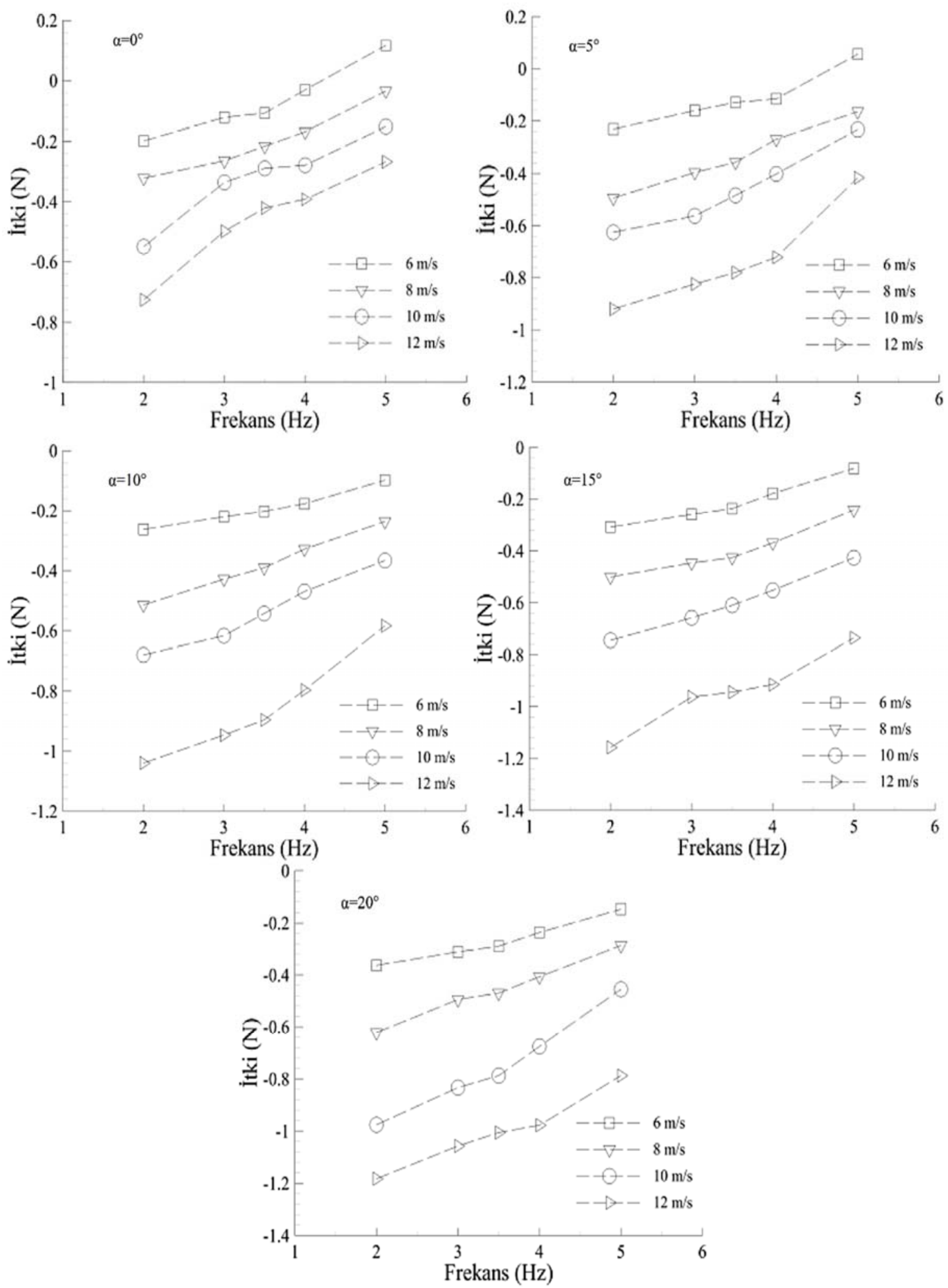

Şekil 16. Lateks kanadın itki kuvvetinin çırpma frekansı ile değişimi (Flapping frequencies and thrust forces for latex wing) 

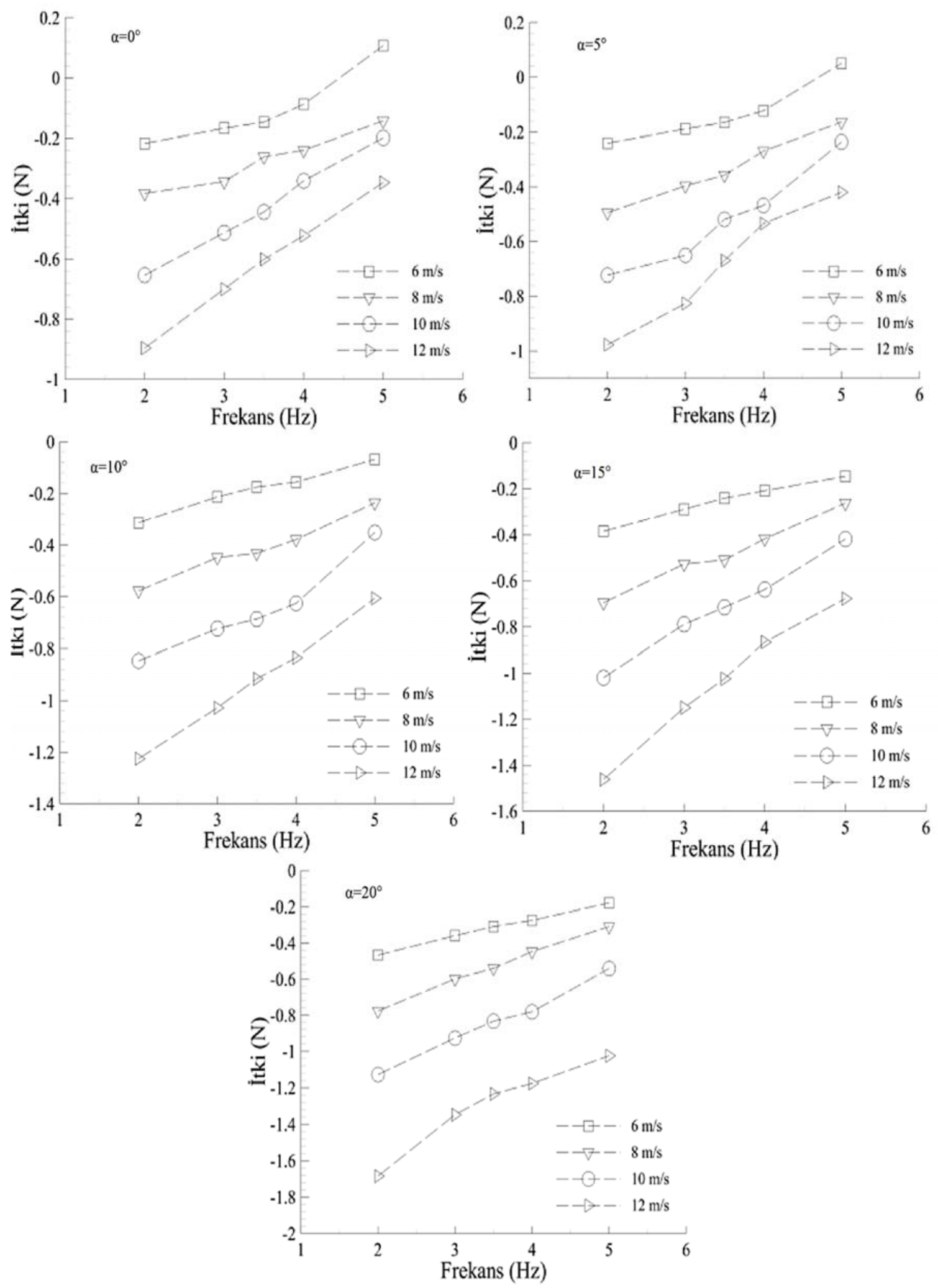

Şekil 17. Ahşap kanadın itki kuvvetinin çırpma frekansı ile değişimi (Flapping frequencies and thrust forces for wood wing) 
Şekil 17'de gösterilen grafiklerde çırpma frekansının artmasıyla itki kuvvetinin arttı̆̆ı, hava hızının artışı ile azaldığı tespit edilmiştir. Şekil 18'de çırpma frekansı ile DC motorun güç tüketimi gösterilmektedir. Güç tüketiminin çırpma frekansı ile orantılı olduğu görülmektedir. Çırpma frekansı artıkça güç tüketimindeki artış daha yüksek olmaktadir.

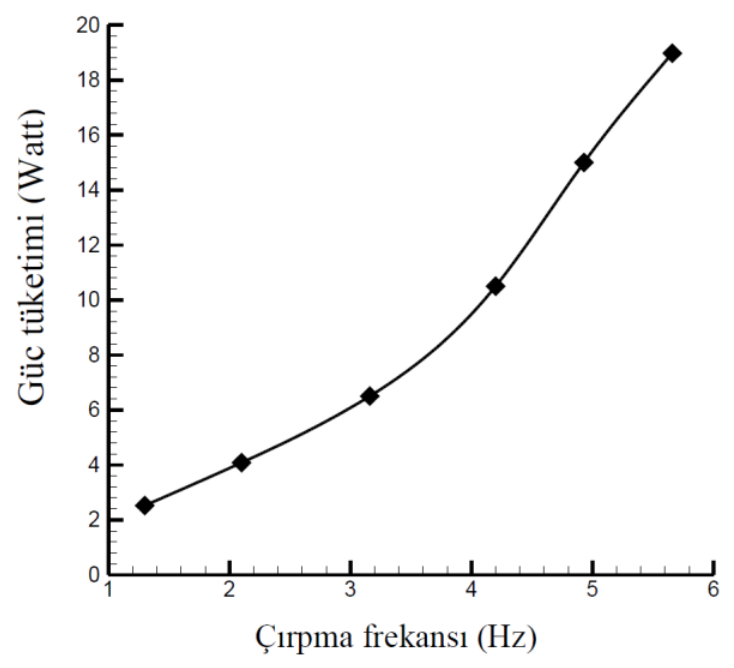

Şekil 18. Güç tüketimi (Power consumption)

\section{SONUÇLAR (CONCLUSIONS)}

Sunulan çalışma ile mikro hava araçlarında kullanılan çırpan kanatların farklı hava hızı, farklı hücum açıları ve farklı çırpma frekanslarındaki taşıma ve itki kuvveti değerleri deneysel olarak incelenmiştir. Çalışma kapsamında bir çırpan kanat mekanizması oluşturulmuş ve üç farklı kanat malzemesi (naylon, ahşap ve lateks) kullanılarak oluşan taşıma ve itki kuvveti değerleri ölçülmüştür. Çırpan kanat mekanizması Cybird P1 ornitopter modelinden esinlenerek tasarlanmıştır. Kanatlar literatürde yer alan örneğe göre ölçeklendirilmiştir. Çırpan kanat mekanizmasına entegre edilen Cybird P1 kanadın deneysel ölçümleri açık devre emmeli tip rüzgar tünelinde gerçekleştirilmiştir. Çalışma için belirlenen hava hızları; $6,8,10$ ve $12 \mathrm{~m} / \mathrm{s}$, hücum açıları ise $0,5,10,15$ ve $20^{\circ}$ 'dir. İtki kuvveti sağlayan çırpma frekans aralığ ise 2, 3, 3,5, 4 ve $5 \mathrm{~Hz}$ olarak belirlenmiştir. Rüzgâr tünelinde yapılan deneyler sonucunda hava hızı ve hücum açısının artmasının taşıma kuvvetini arttırdı ̆̆ değişiminin taşıma kuvvetinde etkin bir farklılık oluşturmadığı tespit edilmiştir. Deneysel çalışması yapılan her bir kanat için $5 \mathrm{~Hz}$ çırpma frekansında en yüksek taşıma kuvveti değeri tespit edilmiştir. Çırpma hareketi sonucunda üretilen itki kuvveti değerleri incelendiğinde, çırpma frekansının itkiyi önemli ölçüde arttırdığı tespit edilmiştir. Bununla birlikte yüksek hücum açısı ve hava hızlarında ise itki kuvveti azalmıştır. En yüksek itki kuvveti $0^{\circ}$ hücum açısı, $6 \mathrm{~m} / \mathrm{s}$ hava hızı ve $5 \mathrm{~Hz}$ çırpma frekansında gerçekleşmiştir. Naylon, ahşap ve lateks malzemelerinden üretilen kanatlar karşılaştırıldığında ise naylon kanadın genel olarak daha iyi itki verimine sahip olduğu belirlenmiştir. Deney sonuçlarının Mazaheri vd. [32] çalışmasında bulunan sonuçlar ile uyumlu olduğu tespit edilmiştir. Çırpan kanatlı hava araçlarında kullanılan kanatlar ile ilgili gelecekte yapılacak çalışmalar için aşağıdaki öneriler dikkate alınması yararlı olacaktır: Deneylere daha küçük boyutlarda dişli mekanizması ve kanat kullanımı toplam ağırlığın azalmasını sağlayacağından daha yüksek çırpma frekanslarında deneysel ölçümler alınabilecektir. Fakat bu avantajlarının yanında üretim maliyetleri artacaktır. Esnekliğe bağlı olarak doğal frekans değerleri sorgulanmalı, elde edilen veriler boyutsuz katsayılara dönüştürülmelidir. Ayrıca deneysel ölçüm maliyetini ve sistem gereksinimini azaltmak ve üretim zamanından tasarruf etmek için daha geniş çalışma şartları ile beraber hesaplamalı akışkanlar dinamiği yazılımları kullanılarak da detaylı incelemeler yapılabilir.

\section{SİMGELER (SYMBOLS)}

$\begin{array}{ll}r_{1} & \text { Rijit gövde bağlantısı boyu } \\ r_{2} & \text { Krank yarıçapı } \\ r_{3} & \text { Bağlama kolu boyu } \\ r_{4} & \text { Çırpan kol boyu } \\ \theta & \text { Bağlantı kollarının açısı } \\ \omega & \text { Bağlantı kollarının açısal hızı } \\ \beta & \text { Bağlantı kollarının açısal ivmesi } \\ \alpha & \text { Hücum açısı }\end{array}$

\section{Kisaltmalar (Abbreviations)}

\begin{tabular}{|c|c|}
\hline $\mathrm{A} / \mathrm{D}$ & Analog / Dijital (Analog / Digital) \\
\hline CTA & $\begin{array}{l}\text { Sabit Sicaklik Anemometresi } \\
\text { (Constant Temp. Anemometer) }\end{array}$ \\
\hline DC & Doğru Akım (Direct Current) \\
\hline $\mathrm{Hz}$ & Frekans \\
\hline İHA & İnsansız Hava Aracı \\
\hline $\mathrm{PC}$ & Kişisel Bilgisayar \\
\hline
\end{tabular}

\section{TEŞEKKÜR (ACKNOWLEDGEMENT)}

$\mathrm{Bu}$ çalışma; Erciyes Üniversitesi Bilimsel Araştırma Projeleri (BAP) Birimi tarafindan FBA-2013-4914 kodlu proje ile desteklenmiştir.

\section{KAYNAKLAR (REFERENCES)}

1. Morman J.J., Literature review of the aerodynamics of flapping flight in micro air vehicle applications, Yüksek Lisans Tezi, North Dakota State University, Mechanical Engineering, North Dakota, 2014.

2. Gerdes J.W., Design, Analysis, and testing of a flapping wing miniature air vehicle, Yüksek Lisans Tezi, University of Maryland, Faculty of the Graduate School, Maryland, 2010.

3. Pourtakdoust S.H., Aliabadi S.K., Evaluation of flapping wing propulsion based on a new experimentally validated aeroelastic model, Scientia Iranica, 19 (3), 472-482, 2012.

4. Hsu C.K., Evans J., Vytla S., Huang P., Development of flapping wing micro air vehicles-design, CFD, 
experiment and actual flight, In 48th AIAA Aerospace Sciences Meeting, Florida, 4-7, 2010.

5. Lin C.S., Hwu C., Young W.B., The thrust and lift of an ornitopter's membrane wings with simple flapping motion, Aerospace Science and Technology, 10 (2), 111-119, 2006.

6. Mukherjee S., Sanghi S., Design of a six-link mechanism for a micro air vehicle, Defence Science Journal, 54 (3), 271-276, 2004.

7. Tsai B.J., Fu Y.C., Design and aerodynamic analysis of a flapping-wing micro aerial vehicle, Aerospace Science and Technology, 13 (7), 383-392, 2009.

8. Karakaş F., Paça O., Köse C., Son O., Zaloğlu B., Fenercioğlu İ., Çetiner O., Çırpan kanatta kanat profilinin etkisi, Journal of Aeronautics and Space Technologies, 7 (2), 55-70, 2014.

9. Liu L., Zhang X., He Z., Aerodynamic analysis and wind tunnel test for flapping-wing mavs, Journal of Theoretical and Applied Information Technology, 45 (2), 542-550, 2012.

10. Shyy W., Aono H., Chimakurthi S.K., Trizila P., Kang C.K., Cesnik C.E., Liu H., Recent progress in flapping wing aerodynamics and aero elasticity, Progress in Aerospace Sciences, 46 (7), 284-327, 2010.

11. Ermeydan A., Kiyak E., Fault tolerant flight control system design to a rotary wing aircraft, Journal of the Faculty of Engineering and Architecture of Gazi University, 32 (1), 21-34, 2017.

12. Nguyen Q.V., Chan W.L., Debiasi M., Hybrid design and performance tests of a hovering insect-inspired flapping-wing micro aerial vehicle, Journal of Bionic Engineering, 13, 235-248, 2016.

13. Tay W.B., Symmetrical and non-symmetrical 3D wing deformation of flapping micro aerial vehicles, Aerospace Science and Technology, 55, 242-251, 2016.

14. Goel M.D., Rawat U., Design and analysis of wing structures of micro air vehicles, In Procedia Engineering, 173, 1602-1610, 2017.

15. Sai K.P.P.M., Bharadwaj K., Design, fabrication and testing of flapping wing micro air vehicle, Int. Journal of Engineering Research and Applications, 6 (1), 133150, 2016.

16. Şenol M.G., Arıkan K.B., Kurtuluş D.F., Dört çubuk mekanizmalı çırpan kanatlı hava aracı yapımı, analizi ve testleri, VI. Ulusal Havacilik ve Uzay Konferansı, Kocaeli Üniversitesi, 2016.

17. Hu H., Kumar A.G., Abate G., Albertani R., An experimental investigation on the aerodynamic performances of flexible membrane wings in flapping flight., Aerospace Science and Technology, 14 (8), 575$586,2010$.

18. Hu H., Kumar A.G., Abate G., Albertani R., An experimental study of flexible membrane wings in flapping flight, 47th AIAA aerospace sciences meeting including the new horizons forum and aerospace exposition, Florida, 2009

19. Yafeng Z., Zhanke L., Wenping S., Bifeng S., Lift and thrust characteristics of the flapping wing micro air vehicle, 27th International Congress of the Aeronautical Sciences, Nice, 2010.

20. Rose C., Fearing R.S., Comparison of ornithopter wind tunnel force measurements with free flight, Robotics and Automation (ICRA), Hong Kong, 2014.

21. Shkarayev S., Silin D., Aerodynamics of flapping-wing micro air vehicles, 47th AIAA Aerospace Sciences Meeting Including the New Horizons Forum and Aerospace Exposition, Florida, 2009.

22. Shkarayev S., Silin, D., Measurements of aerodynamic coefficients for flapping wings at 0-90 angles of attack, AIAA Journal, 50 (10), 2034-2042, 2012.

23. Valiyff A., Harvey J.R., Jones M.B., Henbest S.M., Palmer J.L., Analysis of ornitopter-wing aerodynamics, 17th Australasian Fluid Mechanics Conference, Auckland, 2010.

24. Jones M.B., Valiyff A., Harvey J., Flexibility of an ornitopter wing tested in a wind tunnel, 28th International Congress of the Aeronautical Sciences, Australia, 2012.

25. Nakata T., Liu H., Tanaka Y., Nishihashi N., Wang X., Sato A., Aerodynamics of a bio-inspired flexible flapping-wing micro air vehicle, Bioinspiration \& Biomimetics, 6 (4), 1-11, 2011.

26. Anbarc1 K., Investigation of flow field around flapping wings, Yüksek Lisans Tezi, Istanbul Technical University, Institute of Science and Technology, Istanbul, 2007.

27. $\mathrm{Wu}$ P., Experimental characterization, design, analysis and optimization of flexible flapping wings for micro air vehicles, Doktora Tezi, The University of Florida, Florida, 2010.

28. Nguyen Q.V., Park H.C., Goo N.S., Byun D., Flapping performance and simulation of an insect-mimicking flapper actuated by a compressed unimorph piezoelectric composite actuator, 15th International Symposium on: Smart Structures and Materials \& Nondestructive Evaluation and Health Monitoring, San Diego, 2008.

29. Kim D.K., Kim H.I., Han J.H., Kwon K.J., Experimental investigation on the aerodynamic characteristics of a bio-mimetic flapping wing with macro-fiber composites, Journal of Intelligent Material Systems and Structures, 19 (3), 423-431, 2007.

30. Yeo D., Atkins E., Shyy W., Aerodynamic sensing as feedback for ornitopter flight control, 49th AIAA Aerospace Sciences Meeting, Florida, 2011.

31. Grauer J., Ulrich E., Hubbard J., Pines D., Humbert S., Model structure determination of an ornitopter aerodynamics model from flight data, 48th AIAA Aerospace Sciences Meeting Including the New Horizons Forum and Aerospace Exposition, Florida, 2010.

32. Mazaheri K., Ebrahimi A., Experimental investigation on aerodynamic performance of a flapping wing vehicle in forward flight, Journal of Fluids and Structures, 27 (4), 586-595, 2011. 
33. Şahin İ., Acır A., Numerical and experimental investigations of lift and drag performances of NACA 0015 wind turbine airfoil, International Journal of Materials, Mechanics and Manufacturing, 3 (1), 22-25, 2015.

34. Mazaheri K., Ebrahimi A., Experimental study on interaction of aerodynamics with flexible wings of flapping vehicles in hovering and cruise flight, Archive of Applied Mechanics, 80 (11), 1255-1269, 2010.
35. Harmon R.L., Aerodynamic modeling of a flapping membrane wing using motion tracking experiments, Yüksek Lisans Tezi, University of Maryland, Maryland, 2008.

36. Saygı M.I., Kare model etrafındaki akışın üfleme ve emme ile aktif kontrolünde hücum açısının ve slot kanal konumunun etkisinin deneysel incelenmesi, Yüksek Lisans Tezi, Niğde Üniversitesi, Niğde, 2011. 